\title{
İki Farklı Örneklem Tekniği Kullanılarak Oluşturulan Heyelan Duyarlılık Haritalarının Frekans Oranı (FO) Yöntemi ile Karşılaştırılması
}

\author{
Comparison of the Landslide Susceptibility Maps Using Two Different Sampling Techniques \\ with the Frequency Ratio (FR) Method
}

Gülseren DAĞDELENLER $\mathbb{D}$

Hacettepe Üniversitesi, Mühendislik Fakültesi, Jeoloji Mühendisliği Bölümü, 06800, Beytepe, Ankara

Geliş (Received): 27 Ağustos (August) 2019 / Düzeltme (Revised): 08 Ekim (October) 2019 / Kabul (Accepted): 11 Ekim (October) 2019

\section{ÖZ}

Heyelanların verdiği zararların azaltılması amacıyla heyelan oluşumunun önceden tahmini ve heyelana duyarlı alanların literatürde mevcut yöntemlerle belirlenmesi son derece önemlidir. Bu doğrultuda, heyelanların aynı litolojide geliştiği Bartın ilinin Ulus ilçesinin heyelan duyarlılık haritalamasının yapılması amaçlanmıştır. Çalışmanın önemli noktası, Chebyshev teoreminin bu çalışmada seçilen çalışma alanı için sınanması ve bu yöntemle üretilen duyarlılık haritasının mevcut literatürde sıklıkla kullanılan tüm heyelan kütlesi içerisindeki piksel sayma tekniği ile oluşturulan veri seti kullanılarak üretilen heyelan duyarlılık haritası ile karşılaştırılmasıdır. Çalışma alanında toplam 195 adet heyelan haritalanmış ve heyelanlı ve heyelanlı olmayan alanların belirlenmesinde Chebyshev teoremi ve tüm heyelan kütlesi içerisindeki piksel sayma tekniği olmak üzere iki farklı örneklem tekniği kullanılmıştır. Heyelan duyarlılık analizlerinde kullanılmak üzere topoğrafik yükselik, eğim, bakı, eğrisellik ve NDVI (normalize edilmiş fark bitki örtüsü indeksi) olmak üzere toplam 5 adet parametre haritası üretilmiştir. Her iki örneklem tekniği kullanılarak yapılan duyarlılık analizlerinde literatürde sıklıkla kullanılan Frekans Oranı (FO) yöntemi kullanılmış ve iki farklı harita üretilmiştir. Duyarlılık haritalarının performansı ise Eğri Altında Kalan Alan yöntemine (ROCEAA) göre değerlendirilmiş ve EAA değerleri sırasıyla Chebyshev teoremi için 0.78 ve tüm heyelan kütlesindeki piksel sayılarına göre yapılan örneklem tekniği için ise 0.72 olarak belirlenmiş̧tir. Bu değerlere göre, üretilen her iki duyarlılık haritasının da kabul edilebilir düzeyde olduğu ve Chebyshev teoremi ile örneklem yapılarak üretilen duyarlılık haritasının performansının, diğer örneklem yöntemine göre nispeten daha yüksek çıktığı görülmüştür. Elde edilen bu sonuç, çalışmada kullanılan Chebyshev yönteminin de heyelan duyarlılık haritalama çalışmalarında etkin olarak kullanılabilir alternatif bir yöntem olduğunu ve bu yöntemle üretilen duyarlılık haritasının da başarılı bir kestirime sahip olduğunu göstermiştir.

Anahtar Kelimeler: Chebyshev Teoremi, Eğri Altında Kalan Alan (EAA), Frekans Oranı (FO), Heyelan Duyarlılık, Örneklem Tekniği

\begin{abstract}
In order to reduce the damages caused by the landslides, it is very important to predict the landslide occurrences and to determine the landslide susceptibility areas by the current methods in the literature. In this respect, it is aimed to produce landslide susceptibility maps of Ulus district of Bartin where landslides develop in the same lithology. The important point of the study is that Chebyshev theorem is tested for selected study area in this study and the susceptibility map produced by this method is compared with the landslide susceptibility map produced by using data
\end{abstract}


Dağdelenler

set with pixel counting technique within the entire landslide body which is frequently used in the current literature. A total of 195 landslides were mapped in the study area and two different sampling strategies, Chebyshev's theorem and landslide mass were used in the determination of landslide and non-landslide areas. In this study, landslide susceptibility analysis has been done for the study area by using topographic elevation, aspect, curvature and NDVI parameters. In the susceptibility analysis using both sampling strategies, Frequency Ratio (FO) method, which is frequently used in literature, was used and two different susceptibility maps were produced. The performance of the susceptibility maps was evaluated according to Area Under Curve method (ROC-AUC) and the AUC values were determined as 0.78 for Chebyshev theorem and 0.72 for the sampling technique according to the number of pixels in the entire landslide mass, respectively. According to these values, both susceptibility maps were acceptable and the performance of the susceptibility map produced by sampling with the Chebyshev theorem is relatively higher than the other sampling method. This result shows that Chebyshev method used in the study is an alternative method that can be used effectively in landslide susceptibility mapping studies and that the susceptibility map produced by this method has a successful prediction capacity.

Keywords: Area Under Curve (AUC), Chebyshev Theorem, Frequency Ratio (FR), Landslide Susceptibility, Sampling Technique

\section{GIRIŞ}

Heyelanlar genel olarak kütle hareketleri içerisinde değerlendirilmekte olup, yamaçtaki kaya, toprak ve moloz türü malzemenin yerçekimi etkisiyle yamaç aşağı yöndeki hareketi olarak tanımlanmaktadır (Cruden and Varnes, 1996). Heyelanlar tüm dünyada olduğu gibi ülkemizde de can ve mal kayıplarına neden olan doğal afetlerin başında yer almaktadır. 2016 y1lında Dünya'da meydana gelen doğa kaynaklı toplam 342 adet doğal afet kayıt altına alınmış ve doğa kaynaklı bu afetlerden etkilenen insan sayıs 410 milyon, afetlerde yaşamını yitiren insan sayısı ise 7.628 olarak belirlenmiştir (EMDAT, 2016). Türkiye'de ise 2016 yılında meydana gelen can ve mal kaybına neden olan doğal afet sayısı 323 'tür ve bunların \%20'sini (65 adet) heyelanların oluşturduğu görülmüştür (Ersoy vd., 2017). Ersoy vd. (2017) 2016 yılına ait yaptıkları bu araştırmada doğa kaynaklı afetlerden yaşamını yitiren insan sayısını 83 ve bunlardan 22'sinin heyelan türü doğal afet sırasında yaşamını kaybettiğini vurgulamışlardır. Heyelanların neden olduğu can ve mal kayıplarının önlenmesi amacıyla heyelan duyarlılık çalışmalarına verilen önem gün geçtikçe artmaktadır. Heyelan duyarlılık haritaları, gelecekte olabilecek heyelanlara karşı duyarlı alanları ortaya koymanın yanı sıra herhangi bir alanın heyelan oluşumuna karşı eğilimini de ifade ederler (Aleotti ve Chowdhury, 1999; Guzzetti vd., 1999; Fell vd., 2008; Dağdelenler, 2013). Heyelan duyarlılık çalışmalarında amaç, geçmişte meydana gelen heyelanlardan hareketle, gelecekte oluşabilecek heyelanlı alanların tahminine yönelik çalışmaların gerçekleştirilmesidir. Heyelan duyarlılık harita üretiminde temel unsur, çalışma alanındaki mevcut kütle hareketlerinin mekansal dağılımlarının, yani heyelan envanter bilgisinin doğru ve güvenilir bir şekilde üretilmesidir. Doğru ve güvenilir bir şekilde çıkarılan envanter bilgisi heyelan duyarlılık değerlendirmelerinin yanısıra tehlike ve risk değerlendirmelerinin de temelini oluşturmaktadır (Guzzetti vd., 1999; Van Westen vd., 2008; Fell vd., 2008).

Heyelan duyarlılık haritalama çalışmaları gerek ülkemizde gerekse de dünyada gün geçtikçe artmaktadır. Literatürde son yıllarda heyelan duyarlılık haritalarının üretilmesinde yapay sinir ağları (YSA) (Ercanoğlu, 2005; Melchiorre vd., 2008; Kawabata ve Bandidas, 
2009; Choi vd., 2012; Conforti vd., 2014; Romer ve Ferentinou, 2016; Aditian vd., 2018; Can vd., 2019); bulanık mantık yaklaşımı (Kanungu vd., 2009; Y1lmaz, 2010; Akgün vd., 2011; Ercanoğlu ve Temiz, 2011; Wang vd., 2013; Chen vd., 2017); analitik hiyerarşi yöntemi (AHP) (Komac, 2006; Ercanoğlu vd., 2008; Yalçın vd., 2011; Althuwaynee vd., 2014; Chen vd., 2016); lojistik regresyon (Yeşilnacar ve Topal, 2005; Duman vd., 2006; Nefeslioglu vd., 2008; Tunusluoğlu vd., 2008; Nandi ve Shakoor, 2009; Kundu vd., 2013; Wang vd., 2015; Akgün ve Erkan, 2016); frekans oranı (FO) (Akgün vd., 2008; Yilmaz, 2009; 2010; Pradhan ve Lee, 2010; Akgun, 2012; Ozdemir ve Altural, 2013; Umar vd., 2014) ve destek vektör makinesi (SVM) (Yao vd., 2008; Pradhan, 2013; San, 2014; Tien vd., 2016) gibi değişik yöntemler kullanılmaktadır.

Herhangi bir çalışma alanına ait heyelan duyarlı1ık haritasının oluşturulması, ilk olarak uygun bir haritalandırma biriminin seçimi ile başlamaktadır (Guzzetti vd., 2005). Haritalama biriminin seçimi büyük ölçüde sonraki tüm analizleri ve duyarlılık modellemesini etkiler. Heyelan duyarlılık haritalama çalışmalarında çoğunlukla piksel tabanlı heyelan duyarlılık haritalaması tercih edilmekte ve piksel tabanlı yapılan bu haritalamanın ilk aşamasında heyelan olan ve olmayan alanların çıkarılması yani heyelan envanteri içerisinden örneklemin nereden yapılacağına (tüm heyelan kütlesi veya scarp alanı içerisinde kalan pikseller, scarp noktasına konulan tek bir piksel, veya kök hücre tekniği kullanılarak) çalışmanın amacına uygun bir şekilde karar verilir. Heyelan duyarlılık haritalama çalışmalarında kullanılan örneklem tekniklerinin çalışmanın amacına uygun olarak farkl1lık göstermesi gerekliliği literatürde birçok araştırmacı tarafından dile getirilmiştir (Fernandez vd., 2003; Süzen ve Doyuran, 2004; Clerici vd., 2006; Guzzetti vd., 2006; Görüm vd., 2008; Nefeslioglu vd., 2008; Y1lmaz, 2010; Nefeslioglu vd., 2011; Erener ve Düzgün, 2012; Dağdelenler vd., 2016; Ercanoğlu vd., 2016). Tüm bu mevcut heyelan örneklem tekniklerinden uygun olanının seçilmesi ve heyelan veri setinin de buna göre oluşturulması, sonuç heyelan duyarlılık haritasının doğruluk ve güvenilirliğini, pozitif yönde arttıracaktır. Bunları göz önünde bulunduran Ercanoğlu vd. (2016) yaptıkları çalışmada, heyelanlı ve heyelanlı olmayan alanları çıkartmak diğer bir deyişle heyelan veri setini oluşturmak için literatürde kullanılan tekniklerden farklı olarak Chebyshev teoremini kullanmışlar ve çalıştıkları alanın duyarlılık haritasını oluşturmuşlardır.

$\mathrm{Bu}$ çalışmada, heyelanlı ve heyelanlı olmayan alanların belirlenmesinde Ercanoğlu vd. (2016)'nın önerdiği Chebyshev teoremi ve tüm heyelan kütlesi içerisinde kalan piksellerin sayılması olmak üzere iki farklı teknik kullanılmış ve Bartın ilinin Ulus ilçesine ait iki farklı heyelan duyarlılık haritası literatürde sıkça kullanılan Frekans Oranı (FO) yöntemi kullanılarak üretilmiştir. $\mathrm{Bu}$ farklı iki örneklem tekniği kullanılarak oluşturulan veri setine ait duyarlılık haritalarının performansı ROC Eğrisi Altında Kalan Alan (EAA) yöntemi ile değerlendirilmiş ve birbirleriyle karşılaştırılmıştır. Çalışmada heyelan hazırlayıcı parametrelerden topoğrafik yükseklik, eğim, bakı, eğrisellik ve normalize edilmiş fark bitki örtüsü indeksi (NDVI) dikkate alınmıştır. Çalışmada izlenen yol aşağıda iş-akış diyagramı olarak Şekil 1'de verilmiştir. Chebyshev örneklem tekniğinin bu çalışmada kullanılması ve literatürde sıkça kullanılan başka bir teknikle karşılaştırılması bu çalışmanın özgünlüğünü arttırmakta ve Chebyshev tekniğinin de literatürdeki diğer örneklem tekniklerine alternatif bir teknik olarak kullanılabileceğini vurgulamaktadır. 
Dağdelenler

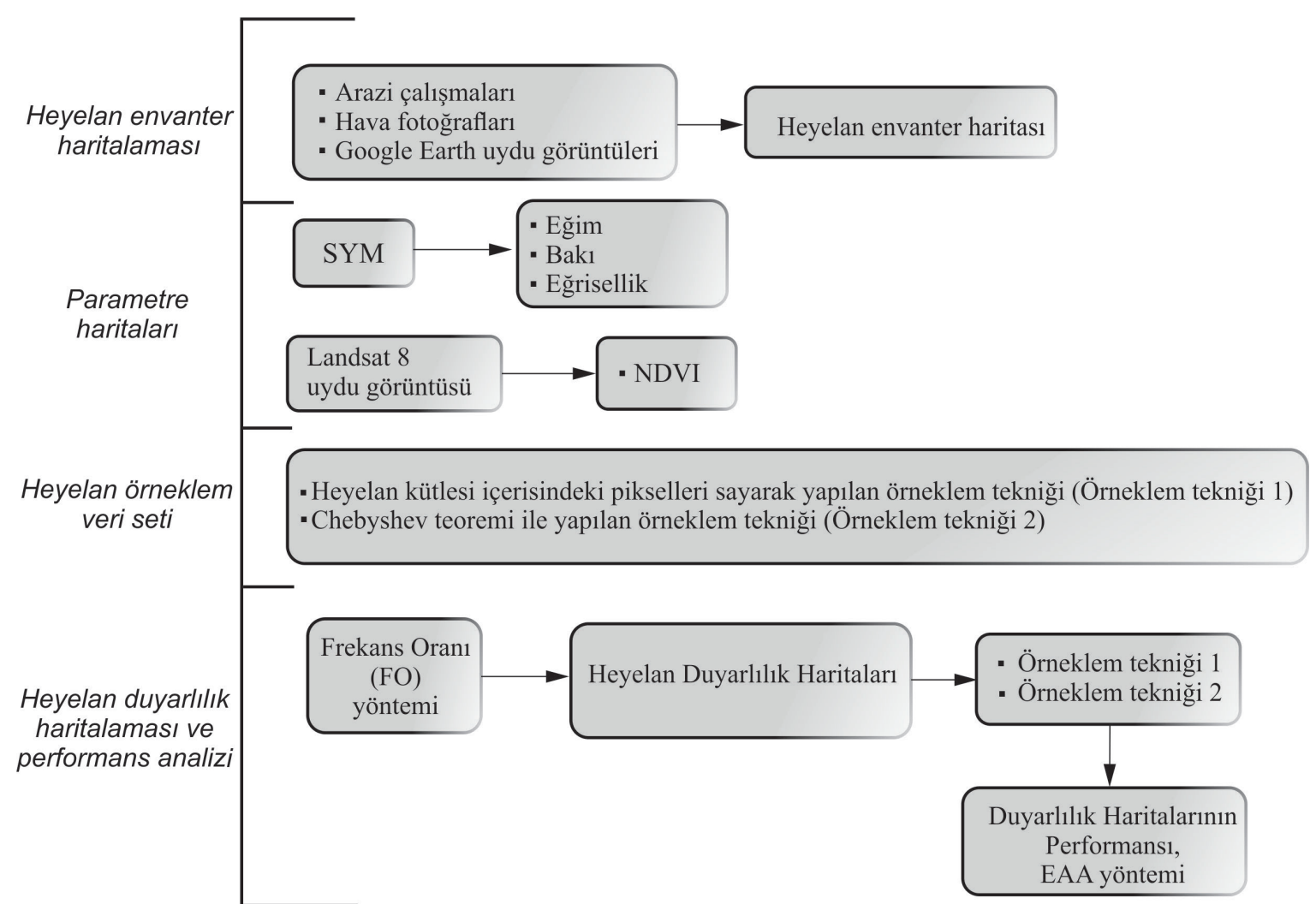

Şekil 1. Çalışmada kullanılan iş-akış diyagramı.

Figure 1. A flow chart used in the study.

\section{ÇALIŞMA ALANI VE JEOLOJISI}

Çalışma alanı olarak, Zonguldak E29d3, E29d4, F29a1 ve F29a2 paftaları içinde yer alan Batı Karadeniz Bölgesindeki Bartın ilinin Ulus ilçesi seçilmiştir (Dağdelenler vd., 2017'den değiştirilerek alınmıştır) (Şekil 2). Çalışma alanı içerisindeki en önemli akarsu yaklaşık KD'dan GB'ya doğru akan Ulus Çayı'dır. Çalışma alanındaki birimler zayıf zemin özellikleri gösterdiğinden çalışma alanının özelliklerinden biri olan yağışın da etkisiyle bölgenin heyelana oldukça duyarlı olduğu görülmektedir. Ulus ilçesinin yıllık ortalama sicaklık 13 derece ve yıllık ortalama yağış miktarı 782 mm'dir. En fazla yağış miktarı yıllık $100 \mathrm{~mm}$ ortalama yağış ile Aralık ayında görülmektedir.
$\mathrm{Bu}$ çalışma kapsamında incelenen Ulus Havzası'nın temel kayaçlarını Üst Jura-Alt Kretase yaşlı krem-gri-koyu gri bozunma ve açık gri-krem-beyaz taze kırık renkli, rekristalize kireçtaşlarından oluşan İnaltı Formasyonu oluştururken bu birimleri üzerleyen Kretase yaşlı Ulus Formasyonu ve yamaç molozu/ alüvyon birimleri örtü kayaçları meydana getirmektedir (Şekil 3). Çalışma alanın büyük bir bölümünde gözlenen Ulus Formasyonu ilk kez Akyol vd. (1974) tarafından Bartın iline bağlı Ulus ilçesi çevresinde tanımlanmış olup en iyi gözlenebildiği yer Karabük-Yenice arasındaki yüzleklerdir. $\mathrm{Bu}$ formasyon, kahverengi-bozkoyu yeşil, ince-orta tabakalı, ince-orta taneli kumtaşı ve koyu yeşil-koyu gri renkli, orta- 
kalın tabakalı şeyllerden oluşan birim önceki çalışmalarda filiş çökelleri olarak tanımlanmıştır (Şekil 3 a). Çalışma alanında bulunan Kuvaterner yaşlı yamaç molozu genellikle yüksek eğim açısına sahip yamaçların eteklerinde yer almakta olup, ince taneli malzeme de içermesinin yanı sıra çoğunlukla, köşeli, gevşek tutturulmuş çakıl ve bloklardan ve ince taneli oluşmaktadır. Çakılların arasında kum, silt ve kilden oluşan bir bağlayıcı malzeme de bulunmaktadır.

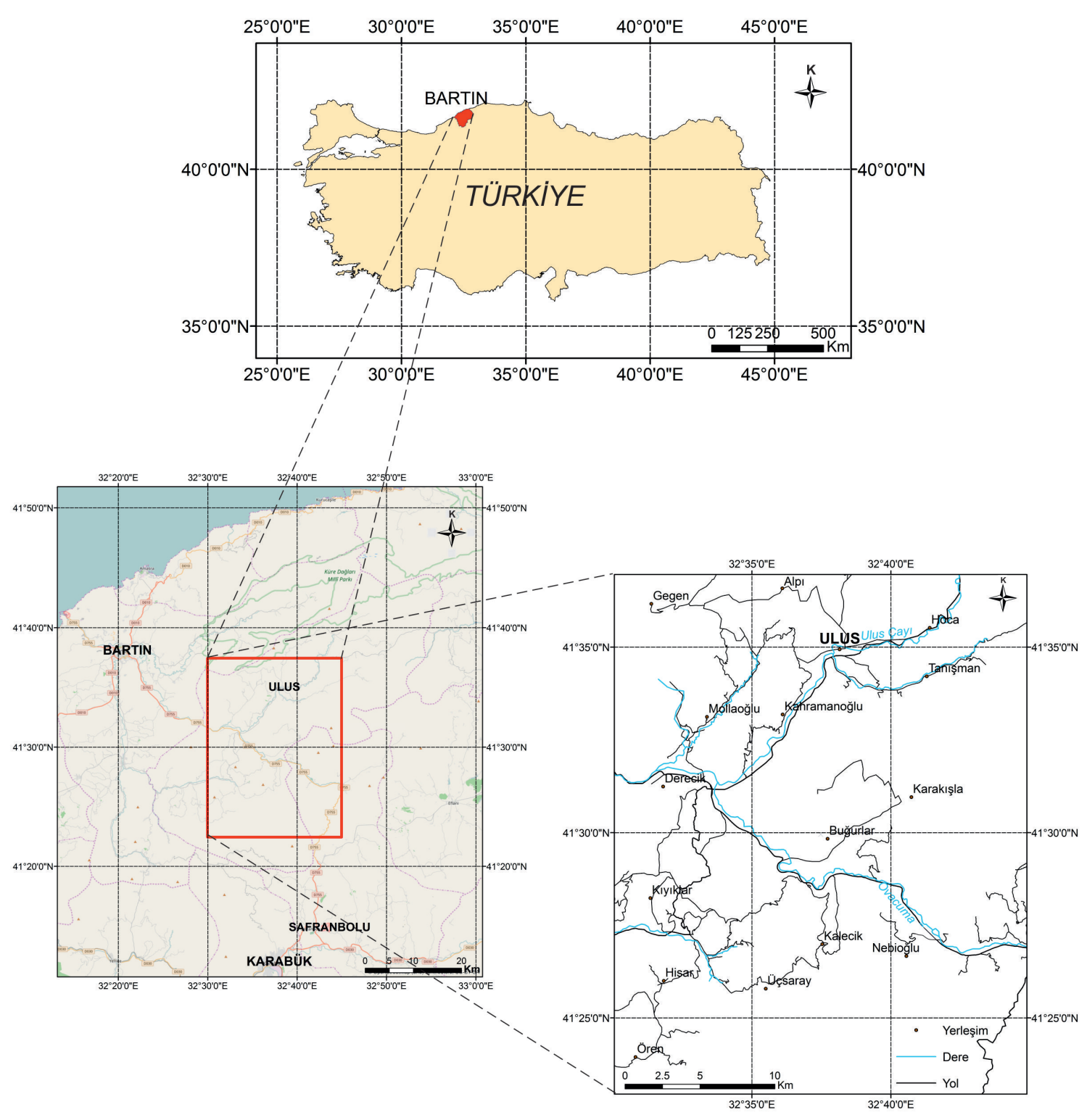

Şekil 2. Çalışma alanının lokasyon haritası (Dağdelenler vd., 2017'den değiştirilerek alınmıştır).

Figure 2. Location map of the study area (modified from Dagdelenler et al., 2017). 
(b)

(a)
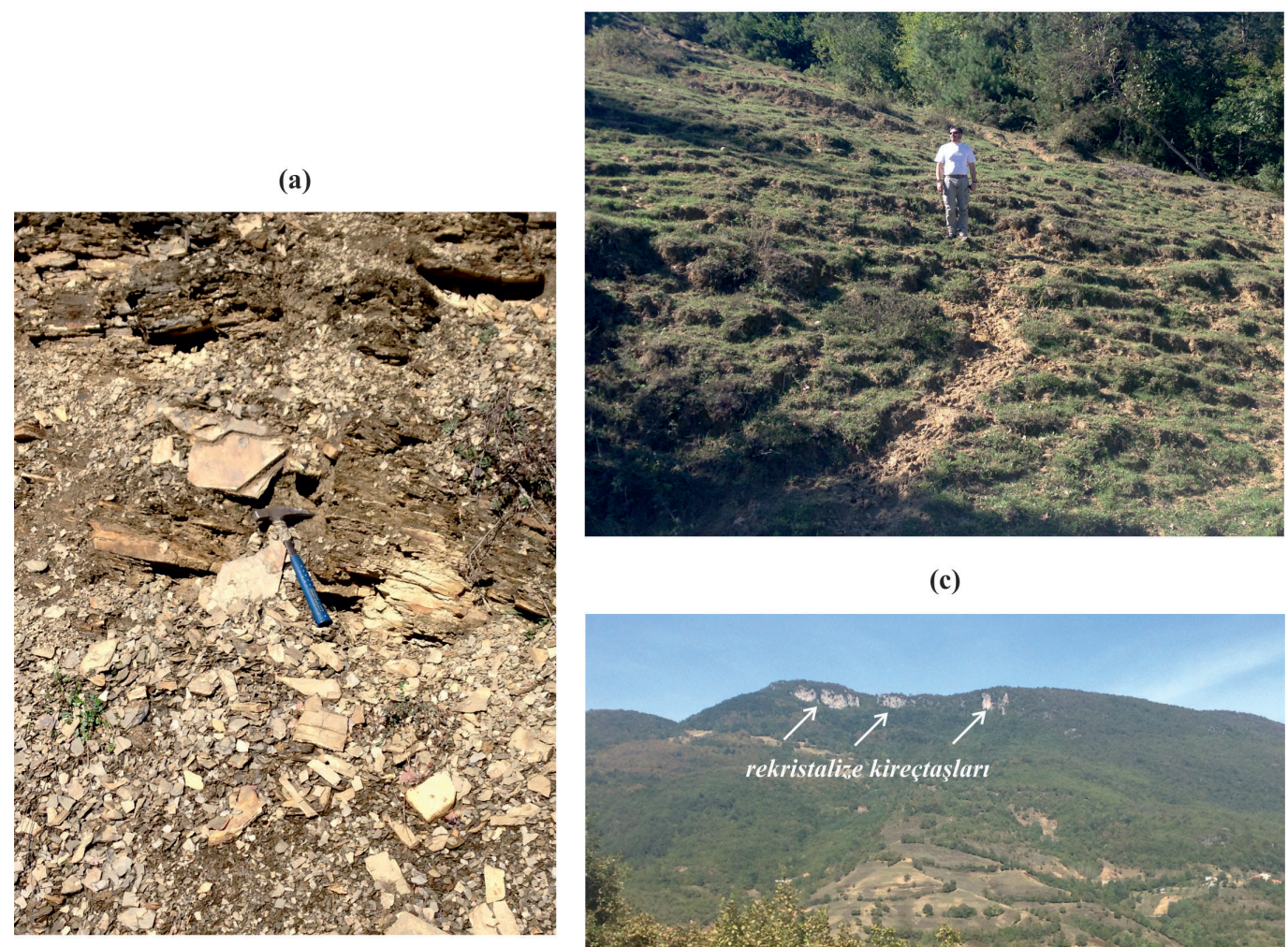

(c)

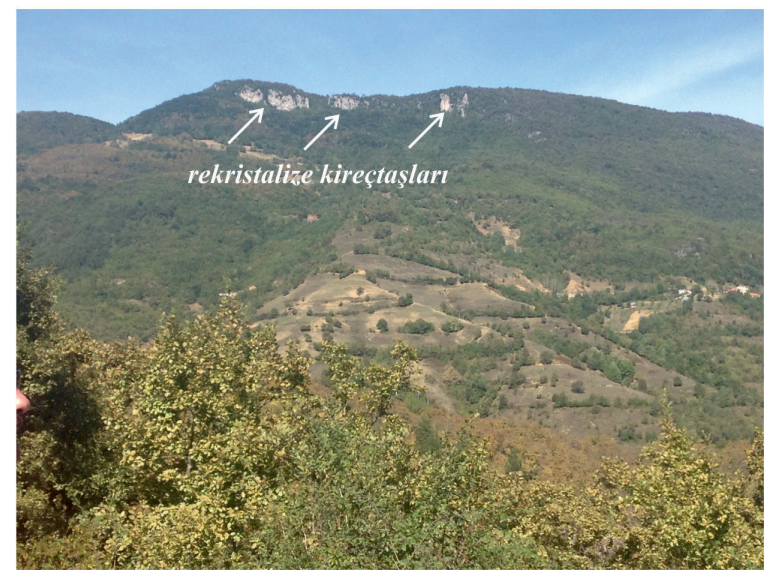

Şekil 3. (a) Karabük-Yenice arası Ulus formasyonunun karakteristik birimi filiş çökellerine, (b) çalışma alanında gözlenen yamaç molozuna ve (c) İnaltı Formasyonunda gözlemlenen kristalize kireçtaşlarına bir örnek.

Figure 3. An example of (a) the flysch deposits of the Karabuk-Yenice characteristic unit of Ulus formation, (b) the talus observed in the study area and (c) the crystallized limestones observed in the Inalti Formation.

\section{MATERYAL VE YÖNTEM}

Literatürde heyelanlı ve heyelansız alanların belirlenmesinde farklı araştırmacılar tarafindan farklı heyelan örneklem teknikleri kullanılmaktadır. $\mathrm{Bu}$ çalışmada öncelikle heyelanlı ve heyelansız alanların belirlenmesinde (örneklem veri setinin oluşturulmasında) tüm heyelan kütlesi içerisindeki piksellerin sayılarak yapıldığ1 örneklem tekniği (örneklem tekniği 1) ve Chebyshev teoremi kullanilarak yapilan örneklem tekniği (örneklem tekniği 2) olmak üzere iki farklı örneklem tekniği kullanılmış ve çalışma alanın bu iki örneklem tekniğine göre heyelan duyarlılık haritaları üretilmiştir. “Örneklem tekniği 1" olarak tanımlanan örneklem tekniği, tüm heyelan kütlesi içerisindeki piksellerin heyelanlı alan olarak; heyelan kütlesi dişarısında kalan piksellerin ise heyelansız alan olarak değerlendirilmesine dayanmaktadır. “Örneklem tekniği 2” ise, Ercanoğlu vd. (2016) 
tarafından literatürde ilk defa önerilen bir yöntem olan heyelanlı ve heyelansız alanlardaki piksellerin "Chebyshev yöntemi" ile belirlendiği tekniktir. $\mathrm{Bu}$ farklı iki yöntemle belirlenen heyelanlı ve heyelansiz alanların heyelan hazırlayıcı parametreler ve çalışma alanının heyelan envanter haritası ile ilişkilendirilerek parametre gruplarının heyelanlarla ilişkisi ortaya konulmuştur. Böylelikle, iki farklı örneklem tekniği için hazırlanan veri tabanı yardımıyla frekans oranı (FO) yöntemi kullanılarak çalışma alanına ait iki farklı heyelan duyarlılık haritası üretilmiştir. Devam eden bölümlerde heyelan duyarlılık haritalamasına kadar yapılan aşamalar sırasıyla anlatılmıştır.

\section{Örneklem Veri Setinin Oluşturulması}

Çalışmanın ilk aşamasında, heyelan duyarlılık analizinde kullanılmak üzere çalışma alanına ait heyelan envanter haritalamas1 yapılmıştır. Yapılan detaylı arazi gözlemleri, alana ait hava fotoğraflarının ve Google Earth uydu görüntülerinin incelenmesi sonucunda çalışma alanında toplam 195 adet heyelanlı alan belirlenmiş ve belirlenen bu heyelan lokasyonları 1/25000 ölçekli topoğrafik haritaya işlenmiştir (Dağdelenler vd., 2017) (Şekil 4). 25 m çözünürlük için toplam $578 \mathrm{~km}^{2}$ lik çalışma alanında, heyelanlı alanlar yaklaşık $103 \mathrm{~km}^{2}$ 'lik bir alanı (165217 piksel) kaplamaktadır ve 195 adet heyelan içerisinde en büyük heyelan alanın ise $10.4 \mathrm{~km}^{2}$ olduğu görülmektedir. Çalışma alanında meydana gelen heyelanların Varnes (1978) heyelan sinıflama sistemine göre çoğunlukla kütlesel derin dairesel kaymalar olduğu gözlemlenmiştir. Çalışma alanında gözlenen heyelanlar ve kayma yönlerine ait örnekler Şekil 5'te görülmektedir.

Çalışmanın ikinci aşamasını, yine heyelan duyarlılık analizlerinde kullanılacak heyelana neden olan parametre haritalarının üretilmesi oluşturmaktadır. $\mathrm{Bu}$ çalışma kapsamında, SYM ve Landsat 8 uydu görüntüsü temel alınarak doğrudan ya da ikincil harita üretimleri gerçekleştirilmiştir. SYM'den itibaren topoğrafik yükseklik (doğrudan), eğim, bak1, eğrisellik (ikincil olarak); Landsat 8 görüntüsü kullanılarak da, çalışma alanının normalize edilmiş fark bitki örtüsü indeksi (NDVI) (aritmetiksel işlemlerle ikincil olarak) haritaları olmak üzere, toplam 5 adet parametre haritası üretilmiştir. Heyelana neden olan bir diğer parametre de litolojidir. Fakat bu çalışmada litoloji duyarlılık analizlerinde girdi parametresi olarak kullanılmamıştır. Litoloji parametresinin girdi parametresi olarak dahil edilmemesinin nedeni, heyelanların hemen hemen hepsinin aynı litolojide (Ulus formasyonu olarak bilinen filiş çökellerinde) meydana gelmesi, farklı iki örneklem tekniği kullanılsa bile duyarlılık analiz sonuçlarında hiçbir değişiklik olmayacağıdır. Çalışma alanı yaklaşık $578 \mathrm{~km}^{2}$ 'lik bir alanı (toplam 1436022 piksel) kaplamaktadır. Çalışma alanına ait sayısal yükseklik modeli (SYM), Harita Genel Müdürlüğü (HGK)'nın 2001 yılına ait $1 / 25000$ ölçekli topoğrafik haritaları $25 \times 25 \mathrm{~m}$ çözünürlükte sayısallaştırma işlemi yapılarak elde edilmiştir (Şekil 6a). Oluşturulan SYM'den ArcGIS 10.3 programının "spatial analyst" modülü kullanılarak eğim, bak1 ve eğrisellik parametre haritaları yine raster veri formatında ve $25 \mathrm{~m}$ mekansal çözünürlüğe sahip olarak üretilmiştir (Şekil 6b,c,d,e). Çalışma alanında yükseklik değerleri $83 \mathrm{~m}$ ile $1570 \mathrm{~m}$ arasında değişmekte olup, ortalama yükseklik değeri 556 m’yi bulmaktadır. Bu çalışmada kullanılan eğim açısı heyelan duyarlılık haritalamasında sıklıkla kullanılan bir parametredir (Cevik ve Topal, 2003; Yalçın ve Bulut, 2007; Yalçın, 2008; Y1lmaz, 2009; Erener ve Düzgün, 2010; Dağ vd., 2011). Çalışma alanındaki eğim değerleri $0^{\circ}-72^{\circ}$ 
arasında değişmekte olup, ortalama eğim $20^{\circ}$ 'yi bulmaktadır. Çalışma alanındaki eğrisellik değerleri topoğrafyanın morfolojik yapısı ile ilgilidir (Lee ve Min, 2001; Erener ve Düzgün, 2010). Çalışma alanına ait eğrisellik haritası Şekil 6 (d)'de görülmektedir. Çalışma alanına ait Landsat 8 ETM+ uydu görüntüsü yardımıyla elde edilen NDVI değerlerine göre alanın bitki yoğunluğu değerlendirilmiştir. Çalışma alanının genelinde NDVI değerleri -0.41-0.2 arasında değişmektedir (Şekil 6e).

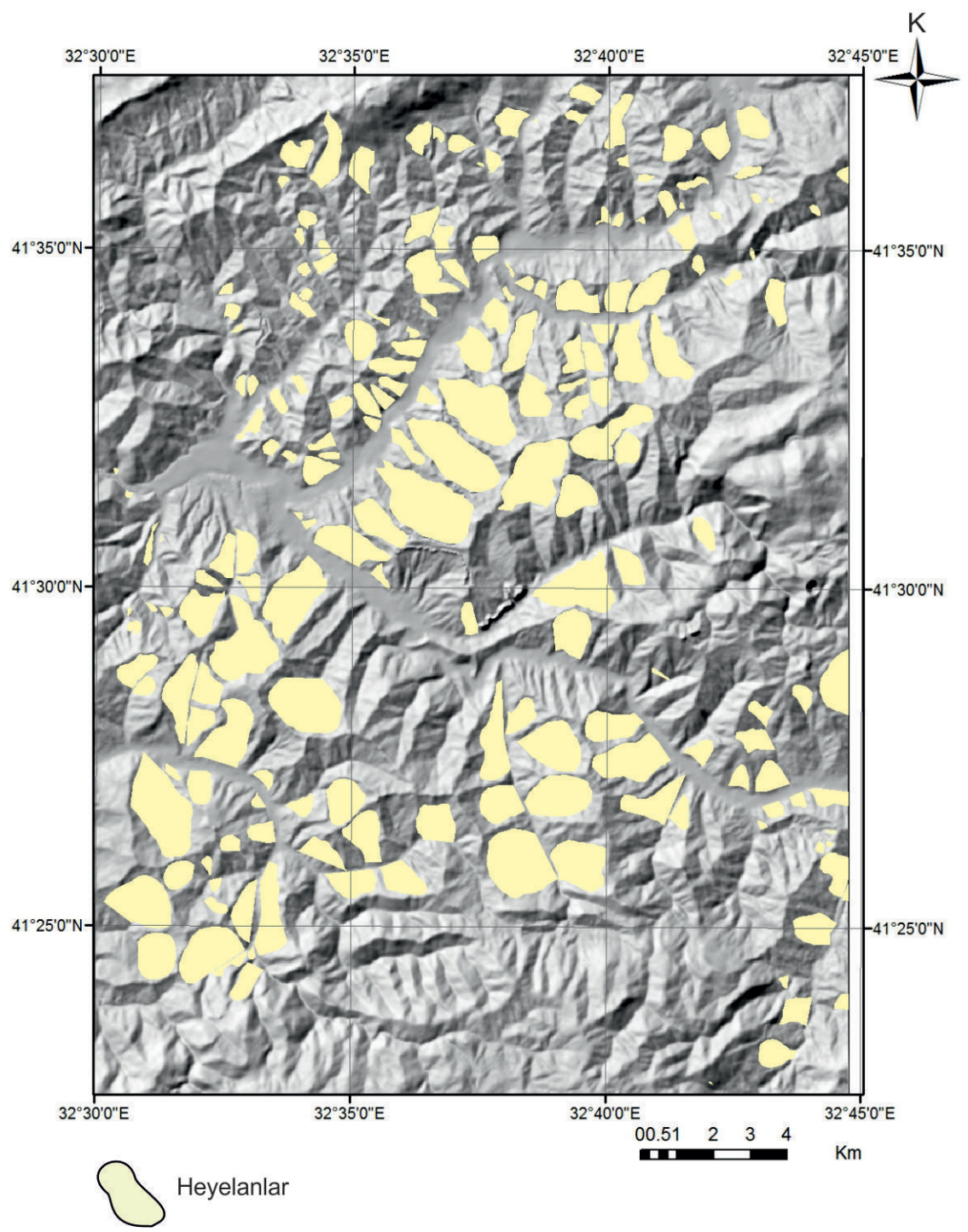

Şekil 4. Çalışma alanında haritalanan heyelanlar (Dağdelenler vd., 2017).

Figure 4. Landslides mapped in the study area (Dagdelenler et al., 2017). 
(a)

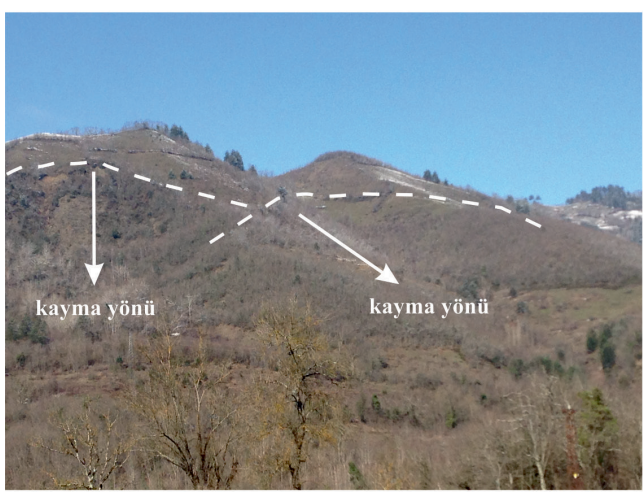

(b)

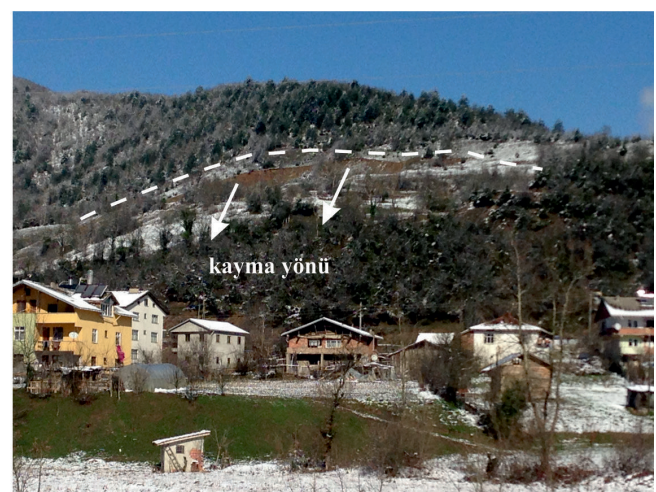

(c)

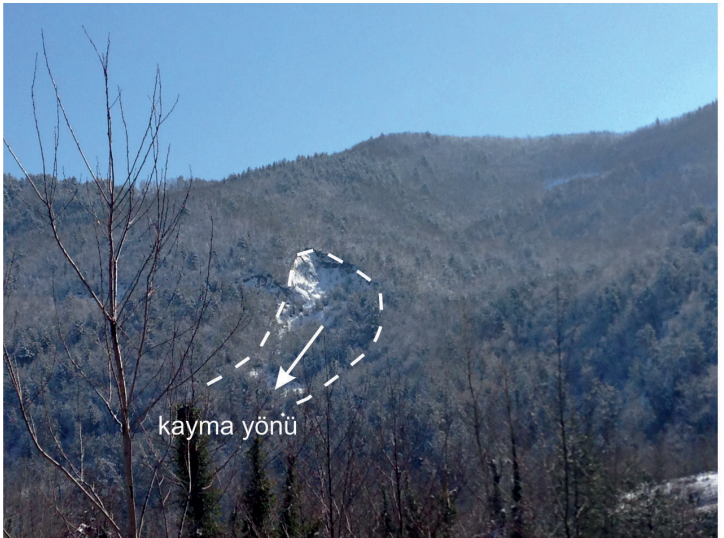

Şekil 5 (a,b,c). Çalışma alanındaki Buğurlar köyü civarında gözlenen heyelanlar ve kayma yönleri.

Figure $5(a, b, c)$. Landslides and sliding directions observed around the Bugurlar village in the study area.

\section{Kullanılan Örneklem Teknikleri}

Heyelan duyarlılık haritalarının üretilmesinde literatürde birçok farklı örneklem veri seti tekniği kullanılmaktadır. Bu çalışmada da veri üretimi için tüm heyelan kütlesi içerisindeki piksel sayılarına göre yapılan (örneklem tekniği 1) ve Chebyshev teoremi kullanilarak yapılan örneklem tekniği (örneklem tekniği 2) olmak üzere iki farklı örneklem tekniği kullanılmış, tüm çalışma alanı, heyelanlı ve heyelansız alanlardaki heyelana neden olan parametrelerin heyelan üzerindeki etkilerinin istatistiksel dağılımları (en küçük, en büyük, ortalama ve standart sapma değerleri) ortaya konulmuştur.
Çalışma alanının rastgele \%75'i modelleme aşamasında, $\% 25$ ' $i$ ise veriyi sınama aşamasında kullanılmıştır. Tüm heyelan kütlesi içerisindeki piksellerin heyelanlı alan olarak, dışarıdaki piksellerin ise heyelansız alan olarak değerlendirildiği örneklem tekniği 1 için topoğrafik yükseklik, eğim, bak1, eğrisellik ve NDVI parametrelerinin çalışma alanı, heyelanlı ve heyelansız alanlardaki istatistiksel dağılımları Çizelge 1'de görülmektedir. Örneklem tekniği 1 için toplam alan 918760 adet pikselden oluşmakta ve bunlardan heyelanlı alan 163733 ve heyelansiz alan ise 755027 piksel sayısına karşı1lık gelmektedir. 
(a)

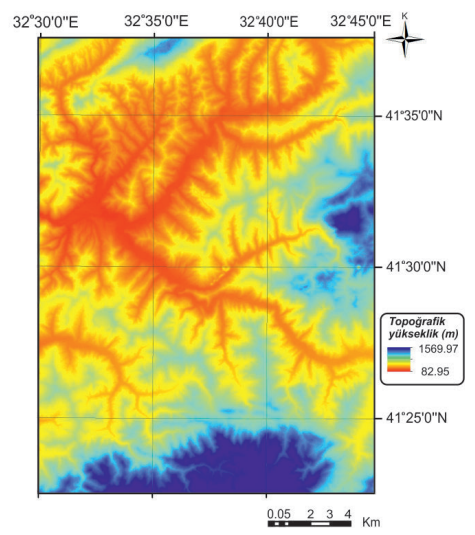

(d)

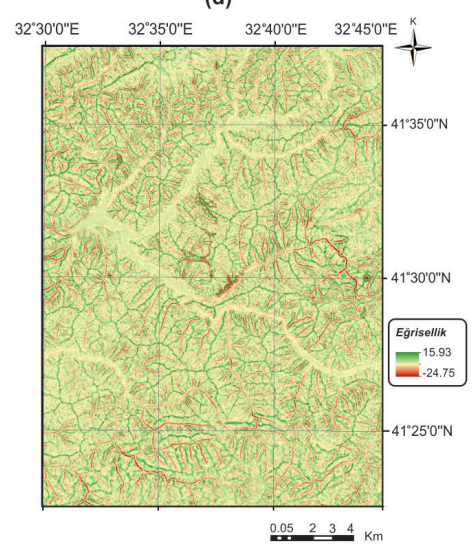

(b)

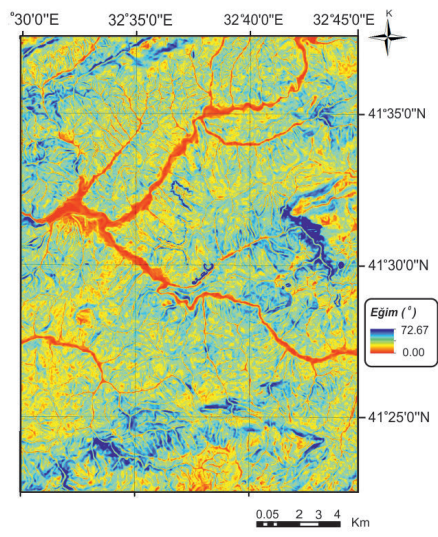

(e)

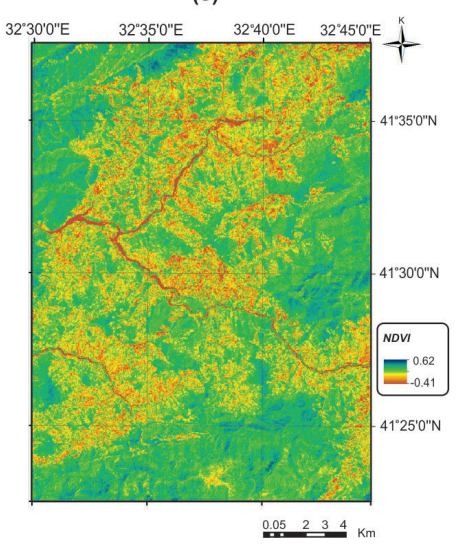

(c)

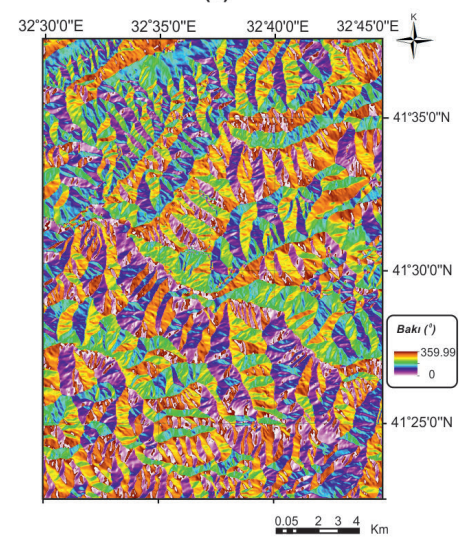

Şekil 6. Çalışmada kullanılan veri tabanı haritaları (a) topoğrafik yükseklik; (b) eğim; (c) bakı; (d) eğrisellik; (e) NDVI.

Figure 6. Database maps used in the study (a) topographical elevation; (b) slope; (c) aspect; (d) curvature; (e) NDVI.

Chebyshev teoremi herhangi bir veri seti veya olasılık dağ 11 lım değerlerinin neredeyse tümünün ortalama değere yakın olmasının sağlandığı ilkesine dayanmaktadır. Diğer bir ifadeyle, bir veri seti veya olasılık dağılım değerlerinin, $\mathrm{k}$ standart sapma değeri ise 1/ $\mathrm{k}^{2}$ oranından daha büyük olmayan oranının, ortalamasından $\pm \mathrm{k}$ standart sapma açıklığı dışında temsil edici olmadığını ifade etmektedir. Ercanoğlu vd. (2016) yaptıkları çalışmada çok sayıda ve türde veri gruplarının içerildiği heyelan değerlendirmelerinde, objektif ve veriye dayalı bir veri tabanı oluşturulabilmesi yönünde katk1 sağlayacağını düşünerek, standart sapma $\mathrm{k}$ değerindeki değişimin göz önünde bulundurulmasıyla; $\mathrm{k}=1.25-3$ arasında değișen değerler için heyelan veri tabanı oluşturmuşlardır. Araştırmacılar, rastgele değişkenin değişim aralığının ya da standart deviasyonunun küçük olmasının o değişkene ait birçok değerin ortalama değere çok yakın olduğunu gösterdiğini buna göre, Chebyshev teoreminde ortalama yaklaşı simetrik herhangi iki değer arasında kalan alan dağılımının standart deviasyonla ilişkili olduğunu vurgulamışlardır. Chebyshev yöntemi aşağıdaki eşitlikle tanımlanmaktadır. 
Çizelge 1. Heyelana neden olan parametrelerin çalışma alanın, heyelanlı ve heyelansız alanlardaki basit istatistiksel dağılımları (örneklem tekniği 1 için).

Table 1. Simple statistical distributions of the parameters causing landslide in landslide and non-landslide areas (for sampling technique 1).

\begin{tabular}{|c|c|c|c|c|c|c|c|c|c|c|c|c|}
\hline \multirow[t]{2}{*}{ Parametre } & \multicolumn{4}{|c|}{ Çalışma Alanı } & \multicolumn{4}{|c|}{ Heyelanlı Alan } & \multicolumn{4}{|c|}{ Heyelansız Alan } \\
\hline & Ort. & En büyük & $\begin{array}{c}\text { En } \\
\text { küçük }\end{array}$ & $\begin{array}{c}\text { Std. } \\
\text { sapma }\end{array}$ & Ort. & En büyük & $\begin{array}{c}\text { En } \\
\text { küçük }\end{array}$ & $\begin{array}{c}\text { Std. } \\
\text { sapma }\end{array}$ & Ort. & En büyük & $\begin{array}{c}\text { En } \\
\text { küçük }\end{array}$ & $\begin{array}{c}\text { Std. } \\
\text { sapma }\end{array}$ \\
\hline $\begin{array}{c}\text { Topoğrafik } \\
\text { yükseklik (m) }\end{array}$ & 556.26 & 1569.97 & 82.95 & 301.14 & 436.84 & 1183.44 & 104.50 & 143.08 & 580.15 & 1569.94 & 82.99 & 319.66 \\
\hline Ĕgim $\left(^{\circ}\right)$ & 20.16 & 72.67 & 0 & 7.98 & 19.13 & 45.78 & 0.60 & 5.55 & 20.36 & 72.41 & 0.05 & 8.20 \\
\hline Bak1 $\left({ }^{\circ}\right)$ & 185.15 & 359.99 & 0 & 107.74 & 178.31 & 359.77 & 0.35 & 99.20 & 186.42 & 359.99 & 0.00 & 105.30 \\
\hline Eğrisellik & 0 & 15.93 & -24.75 & 0.59 & -0.06 & 6.44 & -3.49 & 0.47 & 0.01 & 11.33 & -19.00 & 0.57 \\
\hline NDVI & 0.25 & 0.62 & -0.41 & 0.15 & 0.18 & 0.55 & -0.37 & 0.13 & 0.26 & 0.60 & -0.40 & 0.15 \\
\hline
\end{tabular}

$$
P(\mu-k \sigma)<X<\mu+k \sigma \geq 1-\frac{1}{k^{2}}
$$

P olas1lık, ortalama, k 1'den büyük olan herhangi bir say1, standart deviasyon ve $\mathrm{X}$ ise rastgele değişkeni ifade etmektedir. $\mathrm{Bu}$ teorem, bir rastgele değişkenin k standart sapma aralığında bir değer alması olasılığını tahmin etmektedir (Ercanoğlu vd., 2016).

Ercanoğlu vd. (2016) yaptıkları çalışmada veri gruplarından \pm 2 standart sapma aralığındaki değerleri incelediklerinde herhangi bir verinin bir grupta bulunma olasılığının 0.75 olduğunu hesaplamışlar ve bu değerin de tüm veri setinin en az \%75'ine karş1lik geldiğini belirtmişlerdir. Araştırmacılar, $\mathrm{k}=1.25-3$ standart sapma değerleri ile oluşturulan veri tabanını kullanarak ürettikleri duyarlılık haritalarından en iyi performans $1 \mathrm{k}=2$ standart sapma değeri ile üretilen harita olduğunu vurgulamışlardır. Buradan yola çıkarak bu çalışmada Chebyshev teoremi için $\mathrm{k}=2$ standart sapma değer aralığ 1 için veri seti oluşturulmuş ve analizlerde bu veri tabanı kullanılmıştır. Chebyshev örneklem veri tabanının oluşturulması için her girdi parametresinin standart sapma, ortalama, en büyük ve en küçük değerleri CBS ortamında hesaplanmıştır. Tüm parametreler için $\mathrm{k}= \pm 2$ standart sapma değerleri dikkate alınarak hem heyelanlı hem de heyelanlı olmayan alanlarındaki $\mathrm{k}=2$ standart sapma değerleri hesaplanmış ve veri seti buna göre oluşturulmuştur. Her bir parametrenin (topoğrafik yükseklik, eğim, bak1, eğrisellik ve NDVI) heyelanlı ve heyelansız alanlardaki dağılımları Çizelge 2'de verilmiştir. Örneklem tekniği 2 için toplam alan 895900 adet pikselden oluşmakta ve bunlardan heyelanlı alan 156669 ve heyelansiz alan ise 739231 piksel sayısına karşılık gelmektedir.

\section{HEYELAN DUYARLILIK HARİTALARININ ÜRETILLMESI}

$\mathrm{Bu}$ çalışmada her iki örneklem tekniğine ait heyelan duyarlılık analizleri için Frekans Oranı (FO) yöntemi kullanılmıştır. Lee ve Talib (2005) tarafindan önerilen Frekans Oranı (FO) yönteminde, dikkate alınan parametreler CBS ortamına aktarıldiktan sonra, heyelan envanter haritası ile ilişkilendirilerek, temelde yoğunluk analizleri yapılmaktadır. Frekans Oranı (FO) aşağıdaki eşitlikle hesaplanmaktadır.

$$
F O=a / b
$$

$\mathrm{Bu}$ eşitlikte FO, Frekans Oranı; a katsayısı, parametre alt gruplarındaki heyelanlı piksel sayısının, toplam heyelanlı piksel sayısı oranına; b katsay1s1, parametre alt grubunun dikkate alınan alandaki piksel sayısının, dikkate alınan 
alandaki toplam piksel sayısı oranına karşılık gelmektedir (Lee ve Talib, 2005). Yukarıdaki eşitlikte görüldüğü gibi Frekans Oranı (FO), a katsayısının, b katsayısına bölünmesi sonucunda elde edilmektedir. Kullanılan bu yöntemde FO değerinin 1'den büyük olmas1 parametrenin göreceli olarak heyelan oluşumunda daha etkili olduğu, FO değerinin 1'den küçük olması ise, parametrenin heyelan oluşumunda daha az etkin olduğunu ifade etmektedir (Lee ve Talib, 2005). Bu yaklaşımdan hareketle, FO değerlerini hesaplamak için öncelikle çalışmada her iki örneklem tekniği için de kullanılan 5 ayrı parametrenin sınıf alt grupları oluşturulmuştur. Daha sonra, bu sınıf alt gruplarına düşen o alt gruptaki heyelanlı piksel sayısı(GHPS) ve dikkate alınan alt gruptaki toplam piksel sayıları (GTPS) CBS ortamında belirlenmiştir. Belirlenen bu değerler, sırasıyla ilgili gruba ait heyelanlı piksel sayısına bölünerek a katsayısı; gruptaki toplam piksel değerine bölünerek ise b katsayısı CBS ortamında hesaplanmış ve daha sonra bu değerler birbirine oranlanarak, her bir parametre alt grubu için, FO değeri belirlenmiştir (Çizelge 3 ve 4). Çalışmada kullanılan her bir parametre alt grubu için hesaplanan FO değerleri, ilgili parametreye atanmış ve CBS ortamında çakıştırılmıştır. FO değeri atanmış parametreler daha sonra CBS ortamında toplanarak, heyelan duyarlılık değerleri elde edilmiştir. Belirlenen bu heyelan duyarlılık değerleri çok düşük, düşük, orta, yüksek ve çok yüksek derecede duyarlı olmak üzere 5 sınıfa ayrılmış ve çalışma alanındaki her iki örneklem yöntemine ait heyelan duyarlılık haritaları oluşturulmuştur (Şekil 7a,b).

Duyarlılık haritaları incelendiğinde; örneklem tekniği 1 için ayrılan duyarlılık sınıflarının tercih edilen piksel yüzdeleri; çok düşük $\% 0.94$, düşük $\% 11.05$, orta $\% 21.73$, yüksek \%38.19 ve çok yüksek \%28.09 şeklindedir. Örneklem tekniği 2 kullanılarak üretilen heyelan duyarlılık haritasının duyarlılık sınıflarına bakıldığında ise; piksel yüzdeleri; çok düşük $\% 0.49$, düşük $\% 20.34$, orta $\% 32.90$, yüksek \%28.90 ve çok yüksek \%17.37 şeklinde olduğu görülmektedir.

Çizelge 2. Heyelana neden olan parametrelerin çalışma alanın, heyelanlı ve heyelansız alanlardaki basit istatistiksel dağılımları (örneklem tekniği 2 için).

Table 2. Simple statistical distributions of the parameters causing landslide in landslide and non-landslide areas (for sampling technique 2).

\begin{tabular}{ccccccccc}
\hline Parametre & \multicolumn{9}{c}{ Heyelanlı Alan } & & \multicolumn{3}{c}{ Heyelansız Alan } \\
\cline { 2 - 9 } & Ort. & En büyük & En küçük & Std. sapma & Ort. & En büyük & En küçük & Std. sapma \\
\hline $\begin{array}{c}\text { Topoğrafik } \\
\text { Yükseklik } \\
(\mathrm{m})\end{array}$ & 428.95 & 722.99 & 150.69 & 130.93 & 543.25 & 1491.1 & 82.99 & 286.63 \\
\hline Eğim $\left(^{\circ}\right)$ & 19.05 & 30.13 & 8.03 & 4.88 & 20.40 & 72.41 & 0.00 & 8.19 \\
\hline Bak1 $\left(^{\circ}\right)$ & 178.31 & 359.77 & 0.35 & 99.20 & 186.41 & 359.99 & 0.00 & 105.30 \\
\hline Eğrisellik & -0.06 & 0.88 & -0.99 & 0.38 & 0.01 & 15.33 & -19.00 & 0.57 \\
\hline NDVI & 0.18 & 0.44 & -0.08 & 0.12 & 0.26 & 0.62 & -0.41 & 0.15 \\
\hline
\end{tabular}


Çizelge 3. Örneklem tekniği 1 için hesaplanan her bir parametreye ait frekans oranı (FO) değerleri.

Table 3. Frequency ratio (FR) values for each parameter calculated for sampling technique 1.

\begin{tabular}{|c|c|c|c|c|c|}
\hline Topoğrafik yükseklik (m) & GHPS & GTPS & $\mathbf{a}$ & b & FO \\
\hline $82.95-248.18$ & 16117 & 109082 & 0.098 & 0.119 & 0.83 \\
\hline $248.18-413.40$ & 57173 & 244242 & 0.349 & 0.266 & 1.31 \\
\hline $413.40-578.63$ & 73304 & 217622 & 0.448 & 0.237 & $1.89 *$ \\
\hline $578.63-743.85$ & 13880 & 142722 & 0.085 & 0.155 & 0.55 \\
\hline $743.85-909.08$ & 3146 & 79185 & 0.019 & 0.086 & 0.22 \\
\hline $909.08-1074.30$ & 106 & 46919 & 0.001 & 0.051 & 0.01 \\
\hline $1074.30-1239.52$ & 7 & 40492 & 0.000 & 0.044 & 0.00 \\
\hline $1239.52-1404.75$ & 0 & 32135 & 0.000 & 0.035 & 0.00 \\
\hline $1404.75-1569.97$ & 0 & 6361 & 0.000 & 0.007 & 0.00 \\
\hline \multicolumn{6}{|l|}{ Ĕgim $\left({ }^{0}\right)$} \\
\hline $0-8.08$ & 3185 & 70120 & 0.019 & 0.076 & 0.25 \\
\hline $8.08-16.15$ & 46666 & 197657 & 0.285 & 0.215 & 1.32 \\
\hline $16.15-24.23$ & 84668 & 373982 & 0.517 & 0.407 & 1.27 \\
\hline $24.23-32.30$ & 27507 & 224323 & 0.168 & 0.244 & 0.69 \\
\hline $32.3-40.37$ & 1631 & 46673 & 0.010 & 0.051 & 0.20 \\
\hline $40.37-48.45$ & 76 & 5152 & 0.000 & 0.006 & 0.08 \\
\hline $48.45-56.52$ & 0 & 686 & 0.000 & 0.001 & 0.00 \\
\hline $56.52-64.60$ & 0 & 85 & 0.000 & 0.000 & 0.00 \\
\hline $64.60-72.67$ & 0 & 82 & 0.000 & 0.000 & 0.00 \\
\hline \multicolumn{6}{|l|}{ Bakı ( $\left.{ }^{\circ}\right)$} \\
\hline$-1-0$ (düz) & 0 & 1 & 0.000 & 0.000 & 0.00 \\
\hline $0-45$ & 17153 & 119118 & 0.105 & 0.130 & 0.81 \\
\hline $45-90$ & 21550 & 109897 & 0.132 & 0.120 & 1.10 \\
\hline $90-135$ & 24979 & 110121 & 0.153 & 0.120 & 1.27 \\
\hline $135-180$ & 20288 & 106232 & 0.124 & 0.116 & 1.07 \\
\hline $180-225$ & 18965 & 97372 & 0.116 & 0.106 & 1.09 \\
\hline $225-270$ & 22793 & 106962 & 0.139 & 0.116 & 1.20 \\
\hline $270-315$ & 20750 & 133572 & 0.127 & 0.145 & 0.87 \\
\hline $315-360$ & 17255 & 135485 & 0.105 & 0.147 & 0.71 \\
\hline \multicolumn{6}{|l|}{ Ĕgrisellik } \\
\hline$-24.75--1.55$ & 554 & 8630 & 0.003 & 0.009 & 0.36 \\
\hline$-1.55--0.96$ & 4560 & 34562 & 0.028 & 0.038 & 0.74 \\
\hline$-0.96--0.37$ & 32030 & 160103 & 0.196 & 0.174 & 1.12 \\
\hline$-0.37-0.21$ & 85090 & 416770 & 0.520 & 0.454 & 1.15 \\
\hline $0.21-0.80$ & 36135 & 230602 & 0.221 & 0.251 & 0.88 \\
\hline $0.80-15.93$ & 5364 & 68093 & 0.033 & 0.074 & 0.44 \\
\hline \multicolumn{6}{|l|}{ NDVI } \\
\hline$-0.41--0.29$ & 69 & 1471 & 0.000 & 0.002 & 0.26 \\
\hline$-0.29--0.18$ & 315 & 6902 & 0.002 & 0.008 & 0.26 \\
\hline$-0.18--0.07$ & 5242 & 22901 & 0.032 & 0.025 & 1.28 \\
\hline$-0.07-0.05$ & 23614 & 77025 & 0.144 & 0.084 & 1.72 \\
\hline $0.05-0.16$ & 41063 & 142586 & 0.251 & 0.155 & 1.62 \\
\hline $0.16-0.28$ & 52643 & 207123 & 0.322 & 0.225 & 1.43 \\
\hline $0.28-0.39$ & 33474 & 295930 & 0.204 & 0.322 & 0.63 \\
\hline $0.39-0.51$ & 7277 & 160620 & 0.044 & 0.175 & 0.25 \\
\hline $0.51-0.62$ & 36 & 4202 & 0.000 & 0.005 & 0.05 \\
\hline
\end{tabular}

GHPS: Gruptaki Heyelanl Piksel Saylsl; GTPS: Gruptaki Toplam Piksel Saylsl; a: parametre alt grubundaki heyelanl piksel saylsinin, toplam heyelanl piksel sayısına orani: b: parametre alt grubunun alandaki piksel sayısinin, alandaki toplam piksel saylsina oranı; FO: Frekans Oranı $\sum$ GHPS=163733; $\sum$ GTPS=918760; *: En yüksek FO değeri. 
Çizelge 4. Örneklem tekniği 2 için hesaplanan her bir parametreye ait frekans oranı (FO) değerleri.

Table 4. Frequency ratio (FR) values for each parameter calculated for sampling technique 2.

\begin{tabular}{|c|c|c|c|c|c|}
\hline Topoğrafik yükseklik (m) & GHPS & GTPS & $\mathbf{a}$ & $\mathbf{b}$ & FO \\
\hline $82.95-248.18$ & 15029 & 250662 & 0.096 & 0.287 & 0.34 \\
\hline $248.18-413.40$ & 57002 & 191214 & 0.361 & 0.218 & 1.70 \\
\hline $413.40-578.63$ & 63200 & 155844 & 0.400 & 0.178 & $2.32 *$ \\
\hline $578.63-743.85$ & 21468 & 137350 & 0.143 & 0.134 & 0.89 \\
\hline $743.85-909.08$ & 0 & 72981 & 0.000 & 0.082 & 0.00 \\
\hline $909.08-1074.30$ & 0 & 41360 & 0.000 & 0.047 & 0.00 \\
\hline $1074.30-1239.52$ & 0 & 28719 & 0.000 & 0.033 & 0.00 \\
\hline $1239.52-1404.75$ & 0 & 16360 & 0.000 & 0.019 & 0.00 \\
\hline $1404.75-1569.97$ & 0 & 1410 & 0.000 & 0.002 & 0.00 \\
\hline \multicolumn{6}{|l|}{ Ĕgim $\left(^{\circ}\right)$} \\
\hline $0-8.08$ & 69 & 208981 & 0.000 & 0.233 & 0.00 \\
\hline $8.08-16.15$ & 46666 & 152823 & 0.298 & 0.171 & 1.75 \\
\hline $16.15-24.23$ & 84668 & 293793 & 0.540 & 0.328 & 1.65 \\
\hline $24.23-32.30$ & 25266 & 192159 & 0.161 & 0.214 & 0.75 \\
\hline $32.3-40.37$ & 0 & 42558 & 0.000 & 0.048 & 0.00 \\
\hline $40.37-48.45$ & 0 & 4778 & 0.000 & 0.005 & 0.00 \\
\hline $48.45-56.52$ & 0 & 651 & 0.000 & 0.001 & 0.00 \\
\hline $56.52-64.60$ & 0 & 74 & 0.000 & 0.000 & 0.00 \\
\hline $64.60-72.67$ & 0 & 83 & 0.000 & 0.000 & 0.00 \\
\hline \multicolumn{6}{|l|}{ Bakı $\left(^{\circ}\right)$} \\
\hline$-1-0$ (düz) & 0 & 137068 & 0.000 & 0.169 & 0.00 \\
\hline $0-45$ & 17053 & 91125 & 0.105 & 0.099 & 1.07 \\
\hline $45-90$ & 21450 & 91610 & 0.132 & 0.100 & 1.34 \\
\hline $90-135$ & 21779 & 89712 & 0.153 & 0.098 & 1.39 \\
\hline $135-180$ & 20268 & 92762 & 0.124 & 0.101 & 1.25 \\
\hline $180-225$ & 17966 & 84125 & 0.116 & 0.093 & 1.22 \\
\hline $225-270$ & 21743 & 88129 & 0.139 & 0.096 & 1.41 \\
\hline $270-315$ & 20452 & 115092 & 0.127 & 0.127 & 1.02 \\
\hline $315-360$ & 15988 & 106277 & 0.105 & 0.117 & 0.86 \\
\hline \multicolumn{6}{|l|}{ Ĕgrisellik } \\
\hline$-24.75--1.55$ & 1 & 5938 & 0.000 & 0.007 & 0.00 \\
\hline$-1.55--0.96$ & 740 & 28638 & 0.004 & 0.031 & 0.15 \\
\hline$-0.96--0.37$ & 32028 & 132669 & 0.206 & 0.140 & 1.38 \\
\hline$-0.37-0.21$ & 85090 & 473590 & 0.548 & 0.545 & 1.03 \\
\hline $0.21-0.80$ & 36135 & 195130 & 0.233 & 0.214 & 1.06 \\
\hline $0.80-15.93$ & 2705 & 59890 & 0.010 & 0.064 & 0.26 \\
\hline \multicolumn{6}{|l|}{ NDVI } \\
\hline$-0.41--0.29$ & 52 & 1543 & 0.000 & 0.002 & 0.19 \\
\hline$-0.29--0.18$ & 258 & 6583 & 0.002 & 0.007 & 0.22 \\
\hline$-0.18--0.07$ & 4410 & 24144 & 0.028 & 0.027 & 1.04 \\
\hline$-0.07-0.05$ & 31976 & 100438 & 0.204 & 0.112 & 1.82 \\
\hline $0.05-0.16$ & 38053 & 150802 & 0.243 & 0.168 & 1.44 \\
\hline $0.16-0.28$ & 52303 & 196626 & 0.334 & 0.219 & 1.52 \\
\hline $0.28-0.39$ & 24344 & 252901 & 0.155 & 0.282 & 0.55 \\
\hline $0.39-0.51$ & 5303 & 157867 & 0.034 & 0.176 & 0.19 \\
\hline $0.51-0.62$ & 0 & 4996 & 0.000 & 0.006 & 0.00 \\
\hline
\end{tabular}

GHPS=156699; $\sum$ GTPS=895900; *: En yüksek FO de ğeri 


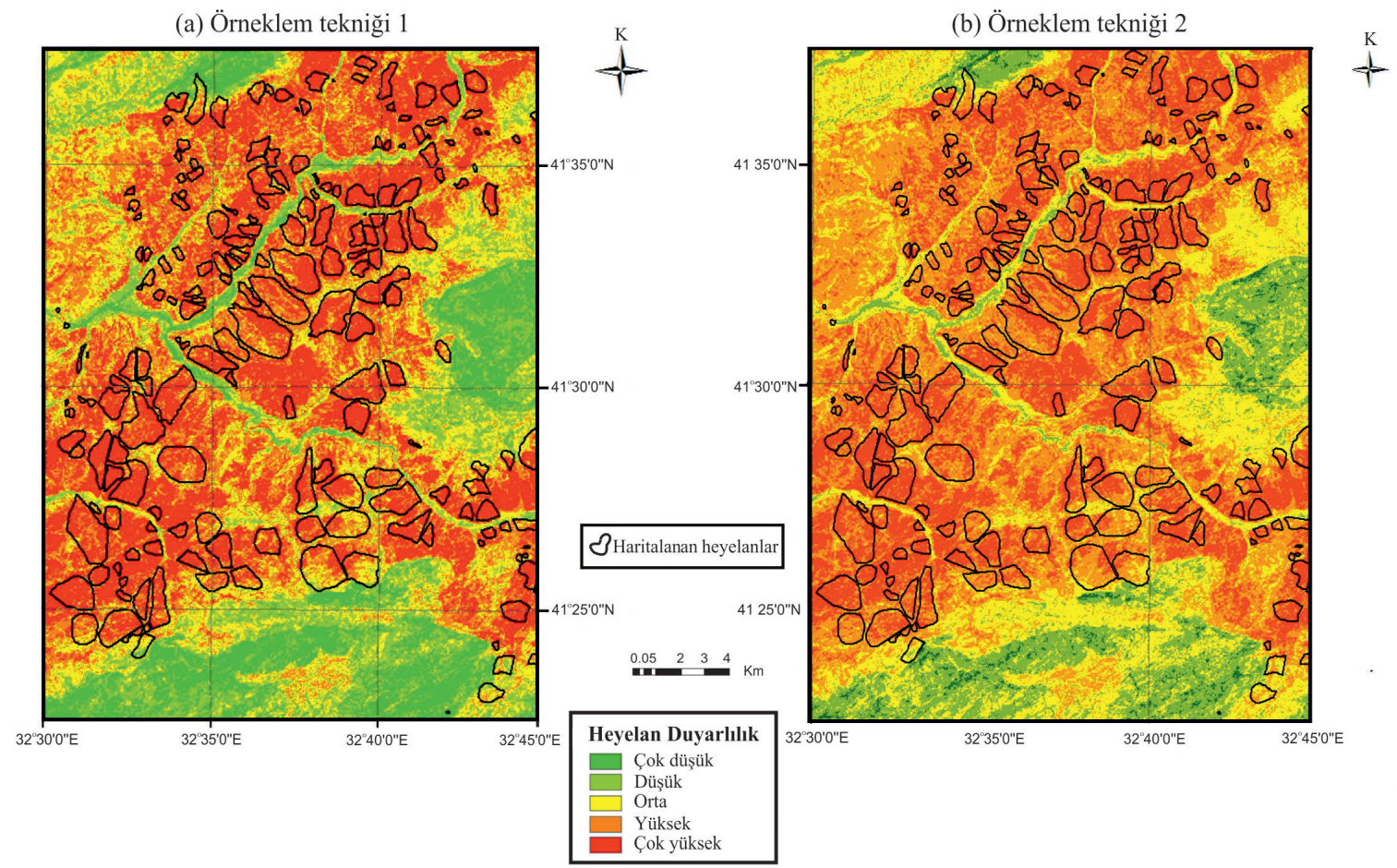

Şekil 7. (a) Örneklem tekniği 1 ile üretilen heyelan duyarlılık haritası ve (b) Örneklem tekniği 2 ile üretilen heyelan duyarlılık haritası.

Figure 7. (a) Landslide susceptibility map produced by sampling technique 1 and (b) Landslide susceptibility map produced by sampling technique 2.

\section{DUYARLILIK HARITALARININ DOĞRULUK DEĞERLENDİRMESİ}

Çalışma kapsamında üretilen heyelan duyarlılık haritalarının doğruluğunun sinanması, diğer bir deyişle, haritaların mevcut heyelanları ne derecede tahmin ettiğinin belirlenmesi gerekmektedir. Heyelan duyarlılık haritalarının doğruluğunun belirlenmesi için literatürde kullanılan birçok yöntem vardır. Bu çalışmada, farklı iki örneklem tekniği (örneklem tekniği 1 ve 2) ile üretilen duyarlilık haritalarının doğruluğunun değerlendirilmesi amaciyla ROC Eğrisi Altında Kalan Alan (EAA) yaklaşımı kullanılmıştır. ROC eğrisi, farklı eşik değerleri için dikey eksen üzerinde doğru pozitiflik (duyarlılık) ve yatay eksen üzerinde yanlış pozitiflik (1-belirlilik) oranlarının yer aldığ 1 bir eğridir (Dirican, 1991; Faraggi ve Reiser, 2002; Obuchowski vd., 2005; Beguiera, 2006; Dağdelenler, 2013). EAA değerinin 1'e yakın olması modelin doğruluğunun yüksek, 0.5 'e yakın olması ise modelin doğruluğunun oldukça düşük olduğunu göstermektedir (Ayalew ve Yamagishi, 2005; Fawcett, 2006; Akgün ve Türk, 2010; Akgün, 2018). Bu çalışmada, EAA değerlerinin belirlenmesi için kontrol veri seti ile Idrisi Selva programının ROC modülü kullanılarak ROC analizi yapılmış ve Minitab 17 istatistiksel yazılım programı kullanılarak her iki model için ROC eğrileri çizilmiştir (Şekil 8). Her iki model için çizilen ROC eğrisinin 0.5 referans çizgisine uzak olduğu görülmektedir. Tüm 
Dağdelenler

heyelan kütlesi içerisindeki pikselleri sayarak yapılan örneklem tekniği (örneklem tekniği 1) ve Chebyshev teoremi ile yapılan örneklem tekniği (örneklem tekniği 2) ile $\mathrm{k}=2$ standart sapma veri seti ile kullanılarak yapılan duyarlıl1k haritalarının performans değerlendirmesi sonucunda belirlenen EAA değerleri sırasıyla örneklem tekniği 1 için 0.78 ve örneklem tekniği 2 için ise 0.72 olarak belirlenmiştir (Şekil 8). çalışmalarında önermiş olduğu Chebyshev teoremi kullanılarak $\mathrm{k}=2$ standart sapma değeri için oluşturulan veri seti ile yapılan ve literatürde sıkça rastlanan rastgele noktalama yöntemi ile yapılan örneklem teknikleri kullanılmış ve karşılaştııılmıştır. Çalışma alanı toplamda 578 $\mathrm{km}^{2}$ 'lik bir alanı kaplamakta olup, alanda toplam 195 adet dairesel kayma özelliğinde heyelan haritalanmıştır. Çalışma alanına ait topoğrafik yükseklik, eğim, bakı, eğrisellik ve NDVI olmak

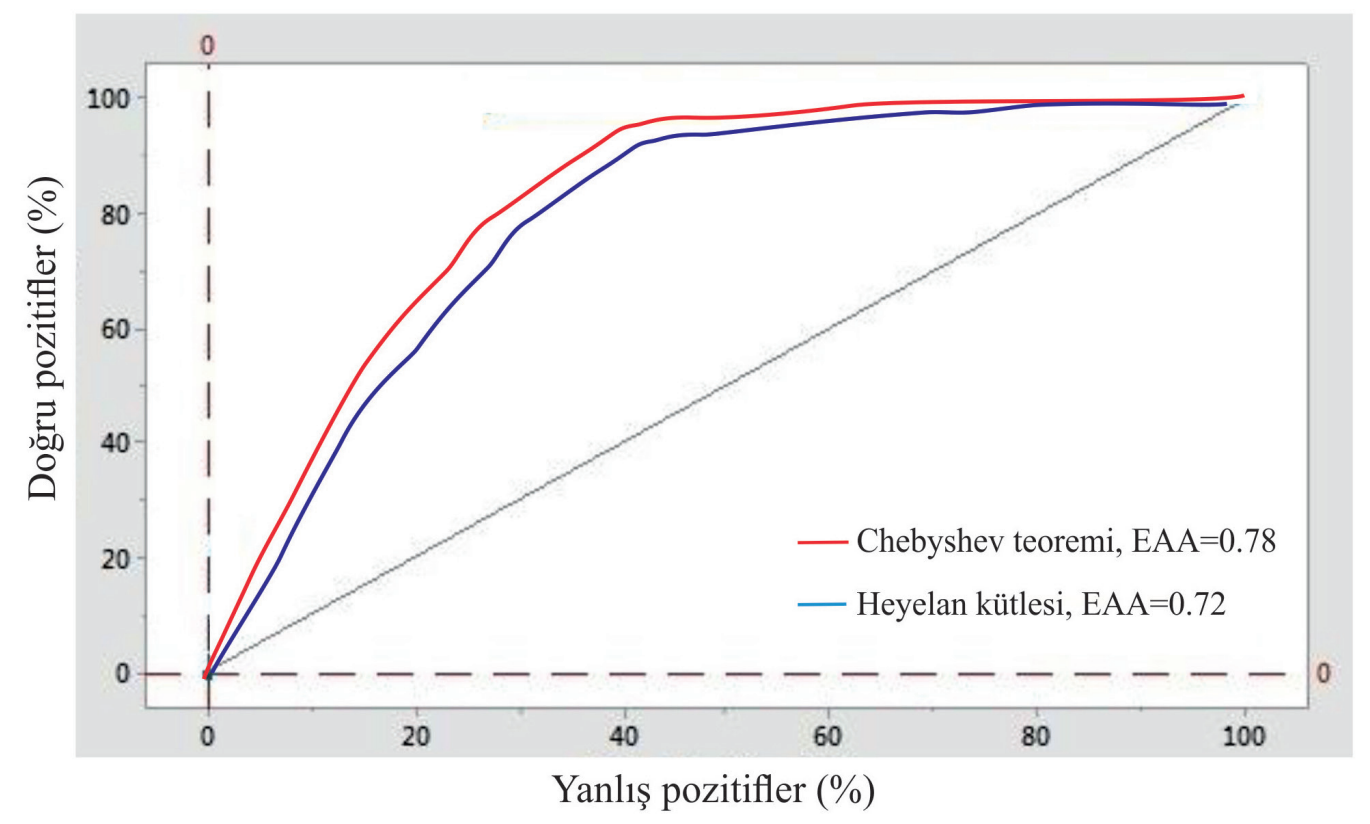

Şekil 8. İki farklı heyelan duyarlıık haritasına ait çizilen ROC eğrileri.

Figure 8. ROC curves of the two different landslide susceptibility maps.

\section{SONUÇLAR VE TARTIŞMA}

Heyelanların sıklıkla meydana geldiği Batı Karadeniz Bölgesinin Bartın ilinin Ulus ilçesinde yapılan bu çalışmada iki farklı örneklem tekniği ile veri seti hazırlanması ve daha sonra aynı çalışma alanı için iki farklı heyelan duyarlılık haritasının frekans oranı (FO) yöntemi ile üretilmesi amaçlanmıştır. Duyarlılık analizleri için veri setinin hazırlanmasında literatüre yeni girmiş olan Ercanoğlu vd. (2016)'nın üzere toplam 5 adet parametre haritas $25 \mathrm{mx} 25 \mathrm{~m}$ çözünürlüğe sahip olacak şekilde oluşturulmuş ve bu parametre haritaları duyarlılık analizlerinde heyelan envanteri ile birlikte girdi parametresi olarak kullanılmıştır. İki farklı örneklem tekniği ile yapılan duyarlılık analizlerinde frekans oranı (FO) yöntemi kullanılmıştır. Heyelan oluşumunda etkili 5 adet parametrenin FO oranı değerlerine bakıldığında; her iki örneklem tekniği için de topoğrafik yüksseklik değerinin 250-580 $\mathrm{m}$ arasında, eğim değerinin de 8-16 
arasında en yüksek FO oranına sahip olduğu, bakı değerlerine bakıldığında ise, en yüksek FO değerlerini GD (örneklem tekniği 1 için)GB (örneklem tekniği 2 için) yönlerinin verdiği görülmektedir. Her iki örneklem tekniğinde de kullanılan bu 5 adet parametre alt gruplarında FO değeri en yüksek olan parametrenin topoğrafik yükseklik parametresi olduğu ortaya çıkmıştır (Bkz. Çizelge 3 ve 4).

Sonraki aşamada, çalışma alanındaki mevcut heyelanlarla, üretilen iki farklı heyelan duyarlılık haritası çakıştırılmıştır. Buna göre, heyelan kütlesi içerisinde kalan piksel sayısına göre üretilen duyarlılık haritasında heyelanların \%28.09'u çok yüksek duyarlı, \%38.19'u yüksek duyarl1, \%21.73'ü orta duyarlı, \%11.05'i düşük duyarlı ve \%0.94'ü ise çok düşük duyarlı sınıfta yer aldığ1; Chebyshev teoremi ile yapılan örnekleme sonucu üretilen duyarlılık haritasında ise heyelanların \%17.37'si çok yüksek duyarl1, $\% 28.90$ '1 yüksek duyarl1, \%32.90'1 orta duyarl1, $\% 20.34$ 'ü düşük duyarlı ve \%0.49'u ise çok düşük duyarlı sınıfta yer aldığı görülmektedir.

$\mathrm{Bu}$ çalışmada heyelan tehlike ve risk değerlendirmelerinin oldukça önemli bir bölümünü oluşturan heyelan duyarll1lk haritalamasında kullanılan farklı iki örneklem tekniği karşılaştırılmıştır. İki farklı örneklem veri seti ile üretilen iki farklı heyelan duyarlılık haritasının doğruluk performans değerlendirmesi Eğri Altında Kalan Alan (EAA) değer yaklaşımı ile yapılmıştır. İki duyarlılık haritasının da doğruluk performansına bakıldığında performans açısından belirgin bir fark bulunmamakla birlikte, mevcut heyelanları temsil etmekte daha yüksek performansa sahip haritanın, Chebyshev teoremi ile yapılan örneklem sonucu üretilen harita olduğu görülmektedir.

Çalışmada dikkate alınan örneklem tekniklerinin birbirine yakın sonuç üretmesinin heyelan envanter haritasının güvenilirliği ile doğrudan ilişkili olduğu söylenebilir. $\mathrm{Bu}$ durum, bu tür çalışmalardaki temel unsurun, heyelan envanter haritasının mevcut heyelanlı alanları ne derecede iyi temsil ettiğinin de bir göstergesi olarak değerlendirilebilir. Diğer bir deyişle, heyelan envanter haritasının kalitesinin/ doğruluğunun/güvenilirliğinin düşük olmas1, değerlendirme veya örnekleme yöntemini, üst düzey algoritmalar içerse bile, olumsuz yönde etkileyeceği açıktır. $\mathrm{Bu}$ nedenle, heyelanlar ve sonucunda oluşabilecek potansiyel hasarların/ zararların en aza indirgenmesindeki temel unsurun, sağliklı ve güvenilir bir heyelan envanteri ve veri tabanın olduğu göz ard1 edilmemelidir.

\section{KATKI BELÍRTME}

$\mathrm{Bu}$ çalışmanın bir bölümü yürütücüsü olduğum Hacettepe Üniversitesi Bilimsel Araştırma Projeleri Koordinasyon Birimi 014 D02 602 006-527 kodlu projenin bir k1sım veri tabanı dikkate alınarak gerçekleştirilmiştir. Yazar, projede araştırmacı olarak görev alan tüm proje ekibine katkılarından dolayı ve ayrıca makaleyi değerlendiren hakemlere de değerli yorumları için teşekkür eder.

\section{KAYNAKLAR}

Aditian, A., Kubota, T., Shinohara, Y., 2018. Comparison of GIS-based landslide susceptibility models using frequency ratio, logistic regression, and artificial neural network in a tertiary region of Ambon, Indonesia. Geomorphology, 318, 101-111.

Akgün, A., Dağ, S., Bulut, F., 2008. Landslide susceptibility mapping for a landslide-prone area (Findikli, NE of Turkey) by likelihoodfrequency ratio and weighted linear combination models. Environmental Geology, 54, 1127-1143.

Akgün, A., Türk, N., 2010. İki ve çok değişkenli istatistik ve sezgisel tabanlı heyelan duyarlılık modellerinin karşılaştırılması: Ayvalık (Balıkesir, Kuzeybatı Türkiye) örneği. Jeoloji Mühendisliği Dergisi, 34(2), 85-112. 
Dağdelenler

Akgün, A, Sezer, E.A., Nefeslioglu, H.A., Gökçeoğlu, C., Pradhan, B., 2011. An easy-to-use MATLAB program (MamLand) for the assessment of landslide susceptibility using a Mamdani fuzzy algorithm. Computers Geosciences, 38(1), 23-34.

Akgün, A., 2012. A comparison of landslide susceptibility maps produced by logistic regression, multicriteria decision and likelihood ratio methods: case study at Izmir, Turkey. Landslides, 9(1), 93-106.

Akgün, A., Erkan, O., 2016. Landslide susceptibility mapping by geographical information systembased multivariate statistical and deterministic models: in an artificial reservoir area at Northern Turkey. Arabian Journal of Geosciences, 9, 165, doi: 10.1007/s12517-015-2142-7.

Akgün, A., 2018. Bulanık Uyarlanabilir Rezonans Teorisi (FuzzyART) Yöntemi Kullanılarak Heyelan Duyarlılık Analizi: Tonya (Trabzon) Örneği. GÜFBED/GUSTIJ 8(1), 135-146. doi: 10.17714/gumusfenbil.346532.

Akyol, Z., Arpat, E., Erdoğan, B., Göğer, E., Güner, Y., Şaroğlu, F., Şentürk, İ., Tütüncü, K. ve Uysal, Ş., 1974. 1/50.000 ölçekli Türkiye Jeoloji Haritası Serisi, Zonguldak E29 a, E29 b, E29 c, E29 d, Kastamonu E30 a, E30 d. MTA Yayınları, Ankara.

Aleotti, P., Chowdhury, R., 1999. Landslide hazard assessment: summary review and new perspectives. Bulletin of Engineering Geology and Environment, 58, 21-44.

Althuwaynee, O.F., Pradhan, B., Park, H.J., 2014. A novel ensemble bivariate statistical evidential belief function with knowledge-based analytical hierarchy process and multivariate statistical logistic regression for landslide susceptibility mapping. Catena, 114, 21-36. doi: 10.1016/ j.catena.2013.10.011.

Ayalew, L., Yamagishi, H., 2005. The application of GIS-based logistic regression for landslide susceptibility mapping in the Kakuda-Yahiko Mountains, Central Japan. Geomorphology, 65, 15-31.

Beguería, S., 2006. Validation and evaluation of predictive models in hazard assessment and risk management. Natural Hazards, 37(3), 315-329.
Can, A., Dagdelenler, G., Ercanoglu, M., Sonmez, H., 2019. Landslide susceptibility mapping at Ovacik-Karabük (Turkey) using different artificial neural network models: comparison of training algorithms. Bulletin of Engineering Geological Environment, 78, 89-102.

Cevik, E., Topal, T., 2003. GIS-based landslide susceptibility mapping for a problematic segment of the natural gas pipeline, Hendek (Turkey). Environmental Geology, 44, 949-962.

Chen, W., Li, W., Chai, H., Hou, E., Li, X., Ding, X., 2016. GIS-based landslide susceptibility mapping using analytical hierarchy process (AHP) and certainty factor (CF) models for the Baozhong region of Baoji City, China. Environmental Earth Sciences, 75, 1-14.

Chen, W., Pourghasemi, H.R., Panahi, M., Kornejady, A., Wanh, J., Xie, X., Cao, S., 2017. Spatial prediction of landslide susceptibility using an adaptive neuro-fuzzy inference system combined with frequency ratio, generalized additive model, and support vector machine techniques. Geomorphology, 297, 69-85.

Choi, J., Oh, H.-J., Lee, C., Lee, S., 2012. Combining landslide susceptibility maps obtained from frequency ratio, logistic regression and artificial neural network models using ASTER images and GIS, Engineering Geology, 124, 12-23.

Clerici, A., Perego, S., Tellini, C., Vescovi, P., 2006. A GIS-Based automated procedure for landslide susceptibility mapping by the conditional analysis method: The Baganza valley case study (Italian Northern Apennines). Environmental Geology, 50, 941-961.

Conforti, M., Pascale, S., Robustelli, G., Sdao, F., 2014. Evaluation of prediction capability of the artificial neural networks for mapping landslide susceptibility in the Turbolo River catchment (Northern Calabria, Italy). Catena, 113, 236-250.

Dağ, S., Bulut, F., Alemdağ, S., Kaya, A., 2011. heyelan duyarlılık haritalarının üretilmesinde kullanılan yöntem ve parametrelere ilişkin genel bir değerlendirme. Gümüşhane Üniversitesi Fen Bilimleri Enstitüsü Dergisi,1(2), 151-176.

Dağdelenler, G., 2013. Heyelan Duyarlılık Haritalarının Üretilmesinde Örneklem ve Doğrulama Stratejilerinin Değerlendirilmesi (Gelibolu Yarımadası'nın Doğu Kesimi). Doktora Tezi, Hacettepe Üniversitesi, Ankara. 
Dağdelenler, G., Nefeslioğlu, H.A., Gökçeoğlu, C., 2016. Modification of seed cell sampling strategy for landslide susceptibility mapping: an application from the Eastern part of the Gallipoli Peninsula (Canakkale, Turkey). Bulletin of Engineering Geology and the Environment, 75, 575-590.

Dağdelenler, G., Ercanoğlu, M., Sönmez, H., Özsayın, E., Güleç, F., 2017. Topoğrafik haritalardan yararlanarak heyelan envanter haritalamasının coğrafi bilgi sistemleri (CBS) ortamında otomatik olarak elde edilmesine yönelik bir çalıșma: Ulus (Bartın) havzası. Hacettepe Üniversitesi Bilimsel Araştırma Projeleri Koordinasyon Birimi, Destek Projesi, Proje No: 014 D02 602 006-527.

Dirican, A., 1991. ROC eğrisi çözümlenmesi ile tanı testlerinin değerlendirilmesi ve bilgisayar uygulamasi. Doktora tezi, İstanbul Üniversitesi Sağlık Bilimleri Enstitüsü, İstanbul.

Duman, T.Y., Can, T., Gokceoglu, C., 2006. Application of logistic regression for landslide susceptibility zoning of Cekmece Area Istanbul Turkey. Environmental Geology, 51(2), 241-256.

EMDAT, 2016. The International Disaster Database. http://www.emdat.be.

Ercanoğlu, M., 2005. Landslide susceptibility assessment of SE Bartin (West Black Sea region, Turkey) by artificial neural networks. Natural Hazards and Earth System Sciences, 5, 979-992.

Ercanoğlu, M., Kasmer, O., Temiz, N., 2008. Adaptation and comparison of expert opinion to analytical hierarchy process for landslide susceptibility mapping. Bulletin of Engineering Geology and Environment, 67, 565-578.

Ercanoğlu, M., Temiz, F.A., 2011. Application of logistic regression and fuzzy operators to landslide susceptibility assessment in Azdavay (Kastamonu, Turkey). Environmental Earth Sciences, 64, 949-964.

Ercanoğlu, M., Dağdelenler, G., Özsayın, E., Alkevli, T., Sönmez, H., Özyurt, N.N., Kahraman, B., Uçar, İ., Çetinkaya, S., 2016. Application of Chebyshev theorem to data preparation in landslide susceptibility mapping studies: an example from Yenice (Karabük, Turkey) region. Journal of Mountain Science, 13(11). doi: 10.1007/s11629-016-3880-z.
Erener, A., Düzgün, H.S.B., 2010. Improvement of statistical landslide susceptibility mapping by using spatial and global regression methods in the case of more and romsdal (Norway). Landslides, 7(1), 55-68.

Erener, A., Düzgün, H.S.B., 2012. Landslide susceptibility assessment: what are the effects of mapping unit and mapping method? Environmental Earth Science, 66, 859-877. DOI 10.1007/s12665-011-1297-0.

Ersoy, Ş., Nurlu, M., Gökçe, O., Özmen, B., 2017. 2016 Yllında Dünyada ve Türkiye'de Meydana Gelen Doğa Kaynaklı Afet Kayıplarının İstatistiksel Değerlendirmesi. Mavi Gezegen, Sayı:22, 13-27 s.

Faraggi, D., Reiser, B., 2002. Estimation of the area under the ROC curve. Stat Med. 21, 3093-3106.

Fawcett,T., 2006. An introduction to ROC analysis. Pattern Recognition Letters, 27, 861- 874.

Fell, R., Corominas, J., Bonnard, C., Cascini, L., Leroi, E., Savage, W.Z., 2008. On behalf of the itc-1 joint technical committee on landslides and engineered slopes: guidelines for landslide susceptibility, hazard and risk zoning for land use planning. Engineering Geology, 102, 85-98.

Fernandez, T., Irigaray, C., El Hamdouni, R., Chacon, J., 2003. methodology for landslide susceptibility mapping by means of a GIS application to the contravies area (Granada, Spain). Natural Hazards, 30(3), 297-308.

Gorum, T., Gonencgil, B., Gokceoglu, C., Nefeslioglu, H.A., 2008. Implementation of reconstructed geomorphologic units in landslide susceptibility mapping: The Melen Gorge (NW Turkey). Natural Hazards, 46(3), 323-351.

Guzzetti, F., Carrara, A., Cardinali, M., Reichenbach, P., 1999. Landslide hazard evolution: a review of current techniques and their applicaton in a multi-scale study, Central Italy. Geomorphology, 31, 181-216.

Guzzetti, F., Reichenbach, P., Cardinali, M., Galli, M., Ardizzone, F., 2005. Probabilistic landslide hazard assessment at the basin scale. Geomorphology, 72, 272-299. 
Dağdelenler

Guzzetti, F., Reichenbach, P., Ardizzone, F., Cardinali, M., Galli, M., 2006. Landslide hazard assessment in the Collazzone area, Umbria, Central Italy. Natural Hazards and Earth System Sciences, 6, $115-131$.

Kanungu, D.P., Arora, M.K., Sarkar, S., Gupta, R.P., 2009. A fuzzy set based approach for integration of thematic maps for landslide susceptibility zonation. Georisk, Vol. 3, Issue 1, 30-43.

Kawabata, D., Bandibas, J., 2009. Landslide susceptibility mapping using geological data, a DEM from ASTER images and an Artificial Neural Network (ANN). Geomorphology, 113, 97-109.

Komac, M., 2006. A landslide susceptibility model using the Analytical Hierarchy Process method and multivariate statistics in perialpine Slovenia. Geomorphology, 74 (1-4), 17-28.

Kundu, S., Saha, A.K., Sharma, D.C., 2013. Remote sensing and gis based landslide susceptibility assessment using binary logistic regression model: a case study in the ganeshganga watershed himalayas. Journal of the Indian Society of Remote Sensing, 41(3), 697-709. doi: $10.1007 / \mathrm{s} 12524-012-0255-\mathrm{y}$.

Lee, S., Talib, J.A., 2005. Probabilistic landslide susceptibility and factor effect analysis. Enviromental Geology, 47(7), 982-990.

Lee, S., Min, K., 2001. Statistical analysis of landslide susceptibility at Yongin, Korea. Environmental Geology, 40, 1095-1113.

Melchiorre, C., Matteucci, M., Azzoni, A., Zanchi, A., 2008. Artificial neural networks and cluster analysis in landslide susceptibility zonation. Geomorphology, 94, 379-400.

Nandi, A., Shakoor, A., 2009. A GIS-based landslide susceptibility evaluation using bivariate and multivariate statistical analyses. Engineering Geology, 110(1-2), 11-20. doi: 10.1016/j.enggeo. 2009.10.001.

Nefeslioglu, H., Gokceoglu, C., Sonmez, H., 2008. An assessment on the use of logistic regression and artificial neural networks with different sampling strategies for the preparation of landslide susceptibility maps. Engineering Geology, 97(3/4),171-191.
Nefeslioğlu, H.A., Gökçeoğlu, C., Sönmez, H., Görüm, T., 2011. Medium-scale hazard mapping for shallow landslide initiation: the Buyukkoy catchment area (Cayeli, Rize, Turkey). Landslides, 8(4), 459-483.

Obuchowski, N.A., 2005. ROC analysis. American Journal of Roentgenology, 184, 364-372.

Ozdemir, A., Altural, T., 2013. A comparative study of frequency ratio, weights of evidence and logistic regression methods for landslide susceptibility mapping: Sultan Mountains, SW Turkey. Journal of Asian Earth Sciences, 64, 180-197.

Pradhan, B., Lee, S., 2010. Landslide susceptibility assessment and factor effect analysis: back propagation artificial neural networks and their comparison with frequency ratio and bivariate logistic regression modelling. Environmental Modelling and Software, 25, 747-759.

Pradhan, B., 2013. A comparative study on the predictive ability of the decision tree support vector machine and neuro-fuzzy models in landslide susceptibility mapping using GIS. Computers \& Geosciences, 51, 350-365. doi: 10.1016/j.cageo. 2012.08.023.

Romer, C., Ferentinou, M., 2016. Shallow landslide susceptibility assessment in a semiarid environment-A Quarternary catchment of KwaZulu-Natal, South Africa. Engineering Geology, 201, 29-44.

San, B.T., 2014. An evaluation of SVM using polygon-based random sampling in landslide susceptibility mapping: The Candir catchment area (western Antalya Turkey). International Journal of Applied Earth Observation and Geoinformation, 26, 399-412. doi:10.1016/j. jag.2013.09.010.

Suzen, M.L., Doyuran, V., 2004. Data driven bivariate landslide susceptibility assessment using geographical information systems: A method and application to Asarsuyu catchment, Turkey. Engineering Geology, 71, 303-321.

Tien Bui, D., Tuan, T., Klempe, H., Pradhan, B., Revhaug, I., 2016. Spatial prediction models for shallow landslide hazards: a comparative assessment of the efficacy of support vector machines, artificial neural networks, kernel logistic regression, and logistic model tree. 
Landslides, 13(2), 361-378. doi:10.1007/ s10346-015-0557-6.

Tunusluoglu, M.C., Gökçeoğlu, C., Nefeslioğlu, H.A. ve Sönmez, H., 2008. Extraction of potential debris source areas by logistic regression technique: A case study from Barla. Besparmak and Kapi Mountains (NW Taurids. Turkey). Environmental Geology, 54: 9-22.

Ozdemir, A., Altural, T., 2013. A comparative study of frequence ratio weights of evidence and logistic regression methods for landslide susceptibility mapping: Sultan Mountains, SW Turkey. Journal of Asian Earth Sciences, 64, 180-197.

Umar, Z., Pradhan, B., Ahmad, A., Jebur, M.N. ve Tehrany, M.S., 2014. Earthquake induced landslide susceptibility mapping using an integrated ensemble frequency ratio and logistic regression models in West Sumatera Province. Indonesia, CATENA, 118, 124-135.

Van Westen, C.J., Castellanos, E., Kuriakose, S.L., 2008. Spatial data for landslide susceptibility, hazard and vulnerability assessment: An overview. Engineering Geology, 102, 112-131.

Varnes, D.J., 1978. Slope Movement Types and Processes. In: Schuster, R.L. and Krizek, R.J., Eds., Landslides: analysis and control, National Research Council, Washington DC, Transportation Research Board, Special Report 176, National Academy Press, Washington DC, 11-33.

Wang, L.J., Sawada, K., Moriguchi, S., 2013. Landslide susceptibility analysis with logistic regression model based on FCM sampling strategy. Computers and Geosciences, 57, 81-92.

Wang, L.J., Guo, M., Sawada, K., Lin, J., Zhang, J., 2015. Landslide susceptibility mapping in Mizunami City, Japan: a comparison between logistic regression, bivariate statistical analysis and multivariate adaptive regression spline models. Catena, 135, 271-282.
Yalçın, A., Bulut, F., 2007. Landslide susceptibility mapping using GIS and digital photogrammetric techniques: A case study from Adresen (NETurkey). Natural Hazards, 41, 201-226.

Yalçın, A., 2008. GIS-based landslide susceptibility mapping using analytical hierarchy process and bivariate statistics in Adresen (Turkey): Comparisons of results and confirmations. Catena, 72, 1-12.

Yalçın, A., Reis, S., Aydınoğlu, A.C., Yomralığlu, T., 2011. A GIS-based comparative study of frequency ratio, analytical hierarchy process. bivariate statistics and logistics regression methods for landslide susceptibility mapping in Trabzon, Ne Turkey. Catena, 85, 274-287.

Yao, X., Tham, L.G., Dai, F.C., 2008. Landslide susceptibility mapping based on support vector machine: a case study on natural slopes of Hong Kong, China. Geomorphology, 101, 572-582.

Yesilnacar, E., Topal, T., 2005. Landslide susceptibility mapping: A comparison of logistic regression and neural networks methods in a medium scale study Hendek region (Turkey). Engineering Geology, 79(3-4), 251-266. doi:10.1016/j. enggeo. 2005.02.002.

Yılmaz, I., 2009. Landslide susceptibility mapping using frequency ratio logistic regression artificial neural networks and their comparison: A case study from Kat landslides (Tokat-Turkey). Computers \& Geosciences, 35(6), 1125-1138. doi: $10.1016 /$ j.cageo.2008.08.007

Y1lmaz, I., 2010. The effect of the sampling strategies on the landslide susceptibility mapping by conditional probability and artificial neural networks. Environmental Earth Sciences, 60(3), 505-519. doi: 10.1007/s12665-009-0191-5. 